\title{
BIDDING DECISION IN LAND AUCTION USING PROSPECT THEORY
}

\author{
Yanyan PENG a, Xinwang LIU a,* \\ ${ }^{a}$ School of Economics and Management, Southeast University, Si Pai Lou 2, Nanjing, 210096, Jiangsu, \\ China
}

Received 2 April 2013; accepted 5 March 2014

\begin{abstract}
Land auction is widely practiced in company and government decisions, especially in China. Bidders are always faced with two or more auctions in the period of a decision cycle. The outcome of the auction is under high risk. The bidder's risk attitude and preference will have a great influence on his/her bidding price. Prospect theory is currently the main descriptive theory of decision under risk. In this paper, we will consider the preferences of the decision-makers in land bidding decisions with the multi-attribute additive utility and reference point method in cumulative prospect theory. Three land auction models are proposed based on the appearance time of the land auctions. The simultaneous model uses cumulative prospect theory without considering the relationships between the auctions. The time sequential model involves the exchange auction decisions at different time with the third-generation prospect theory. The event sequential model further considers the reference point prediction in sequential land auction decisions. The three models can help the decision-makers make better bidding price decision when they are faced with several land auctions in the period of a decision cycle. A case study illustrates the processes and results of our approaches.
\end{abstract}

KEYWORDS: Land auction; Prospect theory; The third generation of prospect theory; Additive utility; Reference point prediction

\section{INTRODUCTION}

Land is a major factor of production for all products. Vacant land is traded in a market mainly by developers, who actively manage development risk for profits (Chau et al. 2010). Over the past decade, urban land supply in China were mainly made by means of auctions. The government makes an announcement about the available land to the public, and the land is sold to the firm who bids at the highest price. In the bidding process, each participant has to submit his bidding price for the land without knowing the others' bidding prices (Chen, Fan 2008). In reality, the whole process can be seen as a first-price sealed auction (Vickrey 1961).

A successful contractor is the one that selects the most optimal bidding price which secures both the contract and contract profitability (Shash, AbdulHadi 1992). Similarly, the successful bidder in land auction is the one who not only wins the land but also obtains the maximum value from the land

\footnotetext{
* Corresponding author. E-mail: xwliu@seu.edu.cn
}

development. An auction is a market institution with an explicit set of rules determining resource allocation and prices on the basis of bids from the market participants (McAfee, McMillan 1987). In an auction, the most important thing for market participants is how to make his or her bidding price. In this paper, we mainly consider participants' bidding price decisions in land auctions. In China, government has the ownership of land, and the real estate company often obtain the use right of land with a fixed time period (usually 70 years) from the government through auction. With the fast development of land market, the land's bidding prices become very high. During the last few years, some plots of land have been bided at very high prices which made these plots of land be called "Di Wang" (the most expensive land). With the high price, many real estate companies often don't have enough fund to bid for many land auctions. Generally for a small real estate company it can only bid for one or two land auctions at a same time due to 
its limited capital, financing condition and the high land bidding prices, though the government may launch many land auctions at a same time.

The real estate bidders are always faced with two or more land auctions in the period of a decision cycle. Considering the appearance time of the latter auction, the bidder might encounter three different situations: (1) The auctions appear at the same time and the bidder needs to decide the bidding prices for the auctions at the same time; (2) The auctions appear at different time, the latter auction is proposed after the bidder has won the former land auctions, but without knowing the development outcomes; (3) The auctions appear at different time and the latter land auction is proposed after the bidder has won the former land auctions and the development outcomes of the former have been known. In China, generally, a small real estate company can only bid for one or two land auctions at a same time. Thus in this paper, the first and the second situations involve two land auctions while the third situation involves more than two auctions (taking four auctions as an example).

The real estate company has the desire to win the land and it needs to estimate the competitors' bidding price, which will make the real estate company obtain the land with more possibility and at a relatively lower price. A scientific estimation on the competitors' bidding price can help the real estate company make a scientific decision of his/her bidding price. If the bidder can estimate his/her competitors' possible bidding prices, then the bidder would have advantages in the auction. Thus, study on the bidders' most possible bidding price is quite necessary.

The competitors' bidding prices are influenced by many factors. Cheng et al. (2011) provided a summary on the most commonly used influential factors, such as the number of competitors, expected profitability, market condition, expected risk, experience in similar project. These factors can be divided into two categories, i.e., numerical factors and non-numerical factors. The numerical factors will be well discussed in the model, while the non-numerical factors are difficult to be described directly in the model. But the non-numerical factors can be included implicitly because the non-numerical factors would impact the numerical factors and the risk. For example, experience in similar project would influence the expected risk and thus influence the expected profitability, while market condition and expected risk would impact the number of competitors, expected profitability and the outcome risk. Additionally, the bidding prices are also influenced by the decision-makers' irrationality and risk preference in real life.

In China, land development has the characteristics of large capital requirement, relatively long development period and high risk of profit. In these high risk situations, the bidder's irrationality would play an important role in the bidder's bidding price decision. Estimating the bidding prices the decision-makers' irrationality and risk preference must be considered. However, traditional expected utility theory (EUT) has an assumption that the decision-maker is perfect rational, which makes the estimating based on traditional expected utility theory fail to describe the decision in real life when the decision-maker is not perfect rational. Actually prospect theory is currently the main descriptive model of decision making under uncertainty. It generalizes expected utility by introducing nonlinear decision weighting and loss aversion. Different from the classical theory, prospect theory adopts a concaveshaped utility function (UF) for gains and convex for losses associated with an inverse S-shaped probability weighting function (PWF) to describe individual preferences in risky prospect choices. Both preference and risk are well considered in decision in prospect theory. A lot of studies have been conducted on prospect theory, including multi attribute and reference point prediction. With prospect theory we can give better explanations to participants' decisions. In this paper, we would utilize prospect theory to give better descriptions of decisions in land auctions.

The article is organized as follows. Section 2 gives a review on the related literature. Section 3 is the preliminary knowledge about prospect theory and its latest developments. Section 4 proposes the theory which will be used in the following sectors to solve decision making problems in land auctions. Section 5 gives the solutions of three independent decision making problems in land auctions using prospect theory. Section 6 summarizes the main conclusion of this paper.

\section{LITERATURE REVIEW}

Studies in the field of competitive bidding strategy models have been conducted since 1950s (Friedman 1956). Numerous models have been developed, some of which were designed specifically for bidders. In spite of the abundance of competitive bidding strategy models that have been developed, most of them were developed using game theory. However, few of them took irrationality into 
consideration, which does affect participants' decisions under uncertainty.

Many studies about bidding price are based on game theory. Study on equilibrium bidding strategies is dated from Vickrey (1961), who analyzed the simplified English auction, Dutch auction, the first price sealed auction and the second price sealed auction under the condition of symmetrical independence private value, obtaining the equilibrium bidding prices for the bidders. Riley and Samuelson (1981) extended the conclusion of Vickrey (1961), obtaining the equilibrium bidding prices for the bidders in more general conditions. Myerson (1981) proposed the equilibrium bidding prices for the bidders in independence private value, from the perspective of mechanism design. Wilson (1977) established a general set of analysis methods for non-collaborate auctions, which can also be used in sealed bidding auctions.

As to multi-attribute auction, McAfee and McMillan (1987) proposed that the factors influencing bidding decision include product quality, characteristics and price. Richard (1980) made similar comment on auctions. They established foundation for multi-attribute auction studies. Chen-Ritzo et al. (2003) and Bichler (2000) put up with the notion that multi-attribute auction is more suitable to the bidders' expectation by experiment. Most studies on multi-attribute auctions are based on game theory (Thiel 1988; Che 1993). Many models have been put up with, while few studies take irrationality of the decision-makers into consideration.

As we have stated above, prospect theory is currently a main descriptive theory of decision under uncertainty. It generalizes expected utility by introducing nonlinear decision weighting and loss aversion. Kahneman and Tversky (1979) proposed prospect theory which explained the major violations of expected utility theory in choices between risky prospects with a small number of outcomes. Since then, a great many studies have been conducted on prospect theory. Rank dependent expected utility (Quiggin 1981, 1982) and cumulative prospect theory (Tversky, Kahneman 1992) are the two main extension forms of the original prospect theory (Kahneman, Tversky 1979). Additionally, the third-generation prospect theory (Schmidt et al. 2008) extends cumulative prospect theory by allowing reference points to be uncertain. Preference is well considered in decision under prospect theory. Prospect theory has been applied to many fields, such as finance, management, investment, etc. With prospect theory, we can gain the most probable bidding price a participant may take in a specific auction. Among the studies that have been conducted on prospect theory, we notice that multi-attribute have been considered into CPT, which is useful for us to analyze decision problem in multi-attribute auctions. Furthermore, studies on reference points are few but are necessary that we will state in the paper later.

Though many studies on bidding prices are conducted using game theory, there are some studies applying prospect theory to auction decisions. Cheng et al. (2011) applied Fuzzy Preference Relations (FPR) and Cumulative Prospect Theory into bidding decision for construction company which is different from our paper, because we consider three situations that a bidder would encounter. Armantier and Treich (2009) interpreted overbidding in first-price auctions using probability weighting function. Xiong and Zhang (2008) discussed the influence on the bidding decision made by loss aversion. Davis et al. (2011) obtained the optimal reserve prices of auctioneers using probability weighting function. Wu et al. (2009) utilized prospect theory to study the interrelationship among the elements embraced in online auction strategy, and stated the influences on the online bidder satisfaction. Ratan (2010) explored the implications of reference-dependent preferences in sealed-bid auctions using prospect theory. And he developed a prospect theory based model to explain bidding in first-price auctions. The difference between our work and the previous work is that we will try to establish different decision models while two or more auctions involved and we will try to solve different decision problems in these land auction models with prospect theory.

In this paper, we aim at making decisions for participants in land auctions using prospect theory. Before the specific problems, we would like to give some preliminaries of prospect theory, which will be applied to solve our land auction problems.

\section{PRELIMINARIES}

\subsection{Cumulative prospect theory}

Cumulative prospect theory (CPT) was proposed by Tversky and Kahneman (1992). Different from the classical theory, CPT adopts a concave-shaped utility function (UF) for gains and convex for losses and an inverse S-shaped probability weighting function (PWF) to describe individual preferences for choosing between risky prospects.

Considering a prospect $P\left(x_{1}, p_{1} ; \ldots ; x_{n}, p_{n}\right)$, with outcomes $x_{1} \geq \ldots \geq x_{k} \geq 0>x_{k+1} \geq \ldots \geq x_{n}$ that are 
associated with probability $p_{1}, \ldots, p_{k}, p_{k+1}, \ldots, p_{n}$. Cumulative prospect theory predicts that people will choose prospects based on the value of the prospect, which is as follows:

$U(X)=C P T\left(x_{1}, p_{1} ; \ldots ; x_{n}, p_{n}\right)=\sum_{i=1}^{n} \pi_{i} u\left(x_{i}\right)$.

In this formula, $u(x)$ is the utility function, while $\pi$ is the decision weighting function. In CPT the utility function $u(x)$ is the same with the one in the original PT, which is concave for gains and convex for losses, with the loss function assumed to be steeper than the gain function. Tversky and Kahneman (1992) proposed $u(x)$ as follows $(\beta>1)$ :

$$
u(x)= \begin{cases}x^{\alpha} & \text { if } x \geqslant 0 \\ -\beta(-x)^{\alpha} & \text { if } x<0\end{cases}
$$

and $x$ in prospect theory is the deviation from the reference point, which is different from the traditional expected utility theory. The decision weights employed in CPT are given by Tversky and Kahneman (1992):

$$
\begin{aligned}
& \pi_{j}=\left\{\begin{array}{l}
\pi_{j}^{+}=w^{+}\left(p_{1}+\ldots+p_{j}\right)- \\
\pi_{j}^{-}=w^{-}\left(p_{j}+\ldots+p_{n}\right)-
\end{array}\right. \\
& w^{+}\left(p_{1}+\ldots+p_{j-1}\right) \quad \text { if } j \geqslant k+1 \\
& w^{-}\left(p_{j+1}+\ldots+p_{n}\right) \quad \text { if } j<k+1
\end{aligned} .
$$

$\pi_{j}^{+}$associated with a positive outcome, is the difference between the capacities of the events "the outcome is at least as good as $x_{j}$ " and "the outcome is strictly better than $x_{j}$ ". $\pi_{j}^{-}$, associated with a negative outcome, is the difference between the capacities of the events "the outcome is at least as bad as $x_{j}$ " and "the outcome is strictly worse than $x_{j}$ ".

The probability functions $w^{+}$and $w^{-}$(are strictly increasing functions from the unit interval into itself, satisfying $w^{+}(0)=w^{-}(0)=0$, and $w^{+}(1)=$ $w^{-}(1)=1$.

\subsection{Third-generation prospect theory}

The third-generation prospect theory (PT3) was proposed by Schmidt et al. (2008). Both the original prospect theory and cumulative prospect theory have a common limitation: the reference points are assumed to be certainties. If reference points are interpreted as endowments or status quo positions, these theories cannot be applied to problems in which a decision-maker is endowed with a lot-

$$
\pi\left(s_{i} ; f, h\right)=\left\{\begin{array}{l}
w^{+}\left(p_{i}\right) \\
w^{+}\left(\sum(j \geqslant i) p_{j}\right)-w^{+}\left(\sum(j>i) p_{j}\right) \\
w^{-}\left(\sum(j \leqslant i) p_{j}\right)-w^{-}\left(\sum(j<i) p_{j}\right) \\
w^{-}\left(p_{i}\right)
\end{array}\right.
$$

tery and has the opportunity to sell or exchange it. Such problems, however, can often be seen in land auctions. For example, a real estate development company is now endowed with a piece of land through auction, while the outcome of the land development has not been certain. At this moment another piece of land is available for bid in the market, would the company exchange the first land for the second one? In these problems alike, we need apply PT3 to predict the company's decision. In addition, PT3 has explained two particularly well-established and robust patterns of deviation from the predictions of conventional expected utility theory. One is that willingnessto-accept (WTA) valuations of lotteries tend to be greater than willingness-to-pay (WTP) valuations (Knetsch, Sinden 1984; Loomes et al. 2003). The second deviation is preference reversal (PR).

The third generation prospect theory (PT3) was proposed by Schmidt et al. (2008). Consider a finite state space $S$, consisting of the states $S_{i}, \ldots, \mathrm{S}_{n}$, and a set of consequences $X$ given by an interval of the real line. Each state $S_{i}$ has an objective probability $p_{i} \geq 0, \sum_{i=1}^{n} p_{i}=1$. Act is defined as an assignment of consequences to states of the world. $F$ is the set of all acts. A particular act $f \in F$ is a function from $S$ to $X$, i.e. an act $f$ specifies for each state $S_{i}$ the resulting consequence $f\left(s_{i}\right) \in X$. A stochastic reference point is modeled as a particular act, the reference act $h$. For any state of the world $S$, we use $f\left(s_{i}\right)$ and $h\left(s_{i}\right)$ to denote the outcomes of act $f$ and act $h$ in state $S_{i}$. Rank the values of $u\left(f\left(s_{i}\right)\right.$, $\left.h\left(s_{i}\right)\right)$. The "gain" states are those for which $f(s)-$ $h(s)$ are positive. And "loss" states are negative.

The value of prospect in PT3 is obtained as follows:

$$
U(f, h)=\sum_{i} u\left(f\left(s_{i}\right), h\left(s_{i}\right)\right) \pi\left(s_{i} ; f, h\right) .
$$

$u\left(f\left(s_{i}\right), h\left(s_{i}\right)\right)$ is a relative value function. $\Pi\left(s_{i} ; f, h\right)$ is the decision weight assigned to state $S_{i}$ when $f$ is being evaluated from $h$. Schmidt et al. (2008) have stated $\Pi\left(s_{i} ; f, h\right)$ in (5). First, let $m^{+}$be the number of states in which there are weak gains and let $m^{-}=\mathrm{n}-\mathrm{m}^{+}$be the number of states in which there are strict losses. Then, reassign subscripts so that, for all subscripts $i, j$, we have $i>j$ if and only if $u\left(f\left(s_{i}\right), h\left(s_{i}\right)\right) \geq u\left(f\left(s_{j}\right), h\left(s_{j}\right)\right)$, and so that the states with weak gains are indexed $m^{+}, \ldots, 1$, while the states with strict losses are indexed $-1, \ldots,-m^{-}$.

$$
\begin{aligned}
& \text { if } i=m^{+} \\
& \text {if } 1 \leqslant i \leqslant m^{+}-1 \\
& \text { if }-m^{-}+1 \leqslant i \leqslant-1 \\
& \text { if } i=-m^{-}
\end{aligned}
$$


$w^{+}$and $w$ - are probability weights for gain states and loss states respectively.

\subsection{Additive utility function in cumulative prospect theory}

Multi-attribute decision making problems have been studied by many researchers. And they have proposed many different methods to solve multi-attribute decision making problems (Zavadskas et al. 2008; Liu 2009; Stankevičienè, Mencaitè 2010; Fan et al. 2013). However, in this paper, we would solve multi-attribute decision making problems with prospect theory. Actually several authors have identified the preference conditions that allow decomposing multi-attribute utility functions into additive, multiplicative and related decompositions (Farquhar 1975; Fischer et al. 1986; Keeney, Raiffa 1993). Most of these decomposition results were derived under expected utility. Abundant evidence exists, however, that expected utility is not valid as a descriptive theory of decision under uncertainty while prospect theory can well describe the decision.

In this sense, additive utility function in prospect theory was proposed by Bleichrodt et al. (2009). Now we review additive utility function in $\mathrm{CPT}$, which is also known as the attribute-specific evaluation (Bleichrodt et al. 2009).

The attribute-specific evaluation interprets reference-dependence for each attribute separately. Denote the reference point on the first attribute by $r_{1}$ and the reference point on the second one by $r_{2} . C=C_{1} \times C_{2}$ is a product of two non-degenerate convex subsets of real line. Outcomes in $C$ will be denoted as $\mathrm{x}=x_{1} x_{2}$ or as $x_{1} x_{2}$ for short. In what follows, the index $i$ will refer to the attributes, and the index $j$ to the states of nature. Hence $f_{j i}$ denotes the $i$-th attribute of the outcome that is obtained under state $j$ with act $f$. A function $U: C \rightarrow$ $\mathrm{R}$ is additive, if $U: x \rightarrow U_{1}\left(x_{1}\right)+U_{2}\left(x_{2}\right)$ where $U_{i}$ is a real-valued function on $C_{i}, i=1,2$ (Bleichrodt et al. 2009).

A prospect $f$ is rank-ordered if $f_{1}>\ldots>f_{n}$. For each prospect, there exist permutations $\rho_{1}$ and $\rho_{2}$, such that $f_{\rho 1}(1) 1>\ldots>f_{\rho 1}(n) 1$ and $f_{\rho 2}(1) 2>\ldots>$ $f_{\rho 2}(n) 2$. Let $P_{\rho 1}=f \in P: f_{\rho 1}(1) 1>\ldots>f_{\rho 1}(n) 1$. That is, $P \rho_{1}$ is the set of all prospects where outcomes are rank-ordered by $\rho_{1} . P \rho_{2}$ is defined similarly. Using additive utility in CPT, we can obtain:

$$
\begin{gathered}
{ }_{\pi_{i}^{(j) i}}^{\text {with }}=w_{i}^{+}\left(\rho_{i}^{(1)}, \ldots, \rho_{i}^{(j)}\right)-w_{i}^{+}\left(\rho_{i}^{(1)}, \ldots, \rho_{i}^{(j-1)}\right), \\
i=1,2 \\
\pi_{\rho_{i}^{(j) i}}^{-}=w_{i}^{-}\left(\rho_{i}^{(j)}, \ldots, \rho_{i}^{(n)}\right)-w_{i}^{-}\left(\rho_{i}^{(j+1)}, \ldots, \rho_{i}^{(n)}\right), \\
i=1,2
\end{gathered}
$$

$\rho_{1}^{(1)}, \ldots, \rho_{1}^{\left(k_{1}\right)}, \ldots, \rho_{1}^{(n)}$ and $\rho_{2}^{(1)}, \ldots, \rho_{2}^{\left(k_{2}\right)}, \ldots, \rho_{2}^{(n)}$ are the rankings of the outcome on the first attribute and the second attribute respectively. The functions $U_{1}$ and $U_{2}$ are strictly increasing and continuous satisfying $U_{1}\left(r_{1}\right)=U_{2}\left(r_{2}\right)=0$. The decision weights $\pi_{\rho_{1}^{(.) 1} \text { and }}^{+} \pi_{\rho_{1}^{(.) 1}}^{-}$are the decision weights for gains and losses for the first attribute. $\pi_{\rho_{2}^{(.) 2}}^{+}$and $\pi_{\rho_{2}^{(.) 2}}^{-}$are the decision weights for gains and losses for the second attribute. $w_{1}^{+}$and $w_{1}^{-}$are the weighting functions for gains and losses for the first attribute. $w_{2}^{+}$and $w_{2}^{-}$are the weighting functions for gains and losses for the second attribute. The utility functions are joint ratio scales and the attribute weighting functions are unique. In the attribute-specific evaluation, the weighting functions may differ across the two attributes (Bleichrodt et al. 2009). So do the utility functions.

\subsection{Reference-point prediction}

Another key factor in prospect theory is reference point. Empirical studies over the past 25 years corroborate that subjects are highly affected by reference points. Reference dependence has a long-standing tradition in psychology and was transferred to behavioral economics with prospect theory. In economic behavior, decision makers seem to derive utility not from their current state of wealth, but from changes in wealth relative to some reference (Camerer 2000). Reference points matter in auctions because of the disposition effect: decision-maker experience resistance to sell at a loss and to hold on at a gain. The disposition effect is explained by the reflection effect of prospect theory (Barberis, Xiong 2009).

In this section, we review a parsimonious formula of reference point prediction. A parsimonious

$P T(f)=\sum_{j=1}^{k_{1}} \pi_{\rho_{1}^{(j) 1}}^{+} U_{1}\left(f(s) \rho_{1}^{(j) 1}\right)+\sum_{j=k_{1}+1}^{n} \pi_{\rho_{1}^{(j) 1}}^{-} U_{1}\left(f(s)_{\rho_{1}^{(j) 1}}\right)+\sum_{j=1}^{k_{2}} \pi_{\rho_{2}^{(j) 2}}^{+} U_{2}\left(f(s) \rho_{2}^{(j) 2}\right)+\sum_{j=k_{2}+1}^{n} \pi_{\rho_{2}^{(j) 2}}^{-} U_{2}\left(f(s) \rho_{2}^{(j) 2}\right) .(6)$ 
formula to predict reference points proposed by Baucells et al. (2011) is as follows:

$$
\begin{aligned}
& r_{n+1}=\rho+\sum_{i=1}^{n} \pi_{n, i} y_{i}, \\
& \sum_{i=1}^{n} \pi_{n, i}=1 .
\end{aligned}
$$

This formula allows for a built-in profit $\rho$ but restrict the sum of weights to one. Built-in profit in this formula possibly reflects some expectation about the future. Baucells et al. (2011) proposed that subjects weight past information in a similar way to how they weight probabilities in a rank-dependent model (Tversky, Kahneman 1992). The "natural" weights for past information is $1 / n$, i.e. equal weighting of each piece of information. Baucells et al. (2011) conducted research on the reference point prediction in behavioral finance, and the transformation from $1 / n$ to $\pi_{n, i}$ works as follows. Firstly, accumulate the natural weights using the ordering of the time line, from more distant to more recent, yielding $i / n, i=1, \ldots, n$. This is in contrast to cumulative prospect theory for gains, where outcomes are ordered from highest to lowest. Next, transform the cumulative weights by means of a weighting function, producing $w(i / n), i=1, \ldots$, $n$. A weighting function, $w$, is any continuous and increasing function from the unit interval into the unit interval, with $w(0)=0$ and $w(1)=1$. Finally, given a weighting function $w$, a built-in profit $\rho$, and a sequence of $n$ prices, the formula they proposed to predict the reference point is:

$$
r_{n+1}=\rho+\sum_{i=1}^{n}[w(i / n)-w((i-1) / n)] y_{i}
$$

We can see that the reference point is determined by three factors: built-in profit, weighting function and the value of $y$. Furthermore, in this prediction, $w$ has the same features with the probability weighting function in prospect theory. This means the value of $y_{1}$ and $y_{n}$ will influence the value of $r_{n+1}$ most.

In the following sections, we would solve several decision problems, which are our main work. All of these bidding decisions are independent for solution. These decision problems would be solved by prospect theory.

\section{LAND AUCTION BIDDING PRICE DECISIONS USING PROSPECT THEORY}

Many studies have been conducted on bidding strategies. However, most of the studies are based on only one auction. Actually, there is not always just one auction available in most cases. Two or more auctions are available and the available auctions might appear at the same moment or different. Here, we will consider the decision-making problems in which there are two or more auctions for bid, and we call these auctions as the first auction,

Situation 1: Simultancous auctions

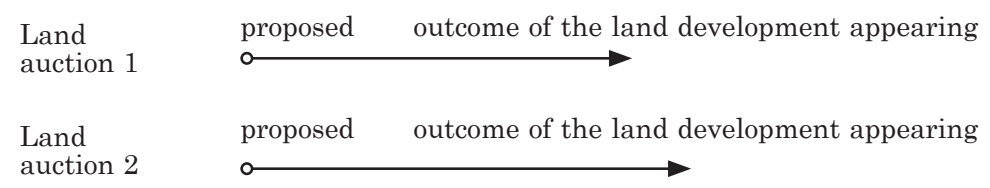

Situation 2: Time-sequential auctions

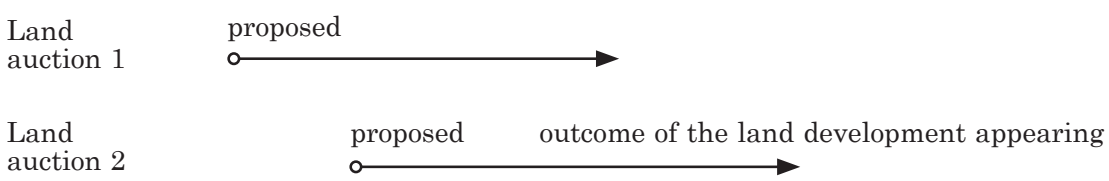

Situation 3: Event-sequential auctions

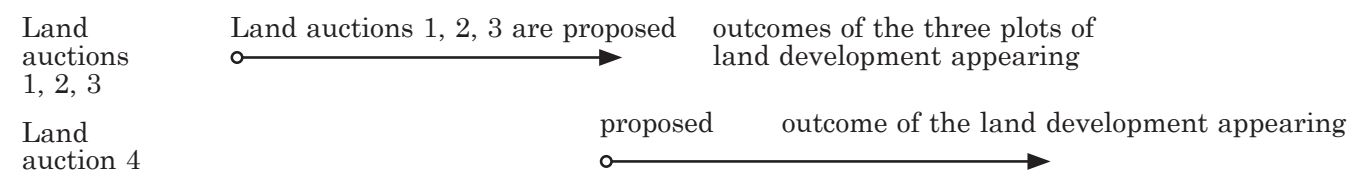

Fig. 1. Three situations of these two auctions 
the second auction, the third, ..., respectively. According to the appearing time of the auctions, there are three situations that a participant might encounter. Thus, we will build three decision models according to the three situations. In China, the land's bidding price has reached to a very high level. With the high price, many real estate companies have no enough fund to bid for many land auctions. Generally, a small real estate company can only bid for one or two land auctions at the same time for its limited financing condition and the high land bidding prices, despite the government may launch many land auctions at the same time. Thus in the first situation and the second situation, we consider two land auctions, while in the third situation, we consider four land auctions. The details of such three situations are discussed in the below and also depicted in Figure 1.

1. The first situation is that the two auctions are available at the same time. In this situation, the decision-maker should make the bidding price for both of the auctions at the same time without knowing the outcomes of the auctions. We call the situation as Simultaneous auctions.

2. The second situation is that the two auctions are available at different time. That is, the second auction is proposed after the first auction has been sold out, but before the development outcome of the first auction is known. In this situation, the decision-maker has to decide whether to abandon the first auction or not. Meanwhile, he or she should decide the acceptable price to abandon the first auction. Furthermore, the optimal psychological bidding price for the second auction should be determined by the decision-maker if he decides to rebid for the second auction. We call the situation as Timesequential auctions.

3. The third situation is that four auctions are available at different time. However, the forth auction is proposed after the outcomes of the previous three auctions have been known. In this situation, the bidding price for the fourth auction should be determined. And intuitively, we predict that the previous outcomes would have influence on the bidding price of the approaching auction. We call the situation as: Event-sequential auctions.

It should be noted that in the case of Situation 3 , the event-sequential auctions mean that the four auctions are available at different time, and the forth auction is proposed after the outcomes of the previous three auctions have been known. That is, after knowing the outcomes of the first three auctions as a whole, we try to calculate the reference point on the basis of the total outcomes of the first three auctions, and also anticipate the outcome of the fourth auction. The outcome of the fourth auction with the reference point is determined by the first three auctions. This is the reason why the event-sequential auction situation still have two phases despite there are four auctions in it.

\subsection{Identifying the key influential factors in land bidding decision}

Before we apply prospect theory to analyze these three situations, we need firstly identify the key influential factors in the land bidding decision. The influential factors for construction company bidding decision have been studied by many researchers (Cheng et al. 2011). Cheng et al. (2011) gave a summary of 44 factors identified in the literature as affecting bid/no bid decision making for construction companies. And these factors were incorporated into a questionnaire and sent to the bidders. The bidders were asked to assign an importance score to each factor on a scale from 1 to 9 . The higher the score was, the more important the factor was felt by the bidder. Cheng et al. (2011) conducted the survey and described those factors which have received average score of importance equal to or greater than 5 in Table 1.

Table 1. Key influential factors in the bidding decision

\begin{tabular}{ll}
\hline Category & Factor \\
\hline Project & Project size \\
Resources & Experience for similar project \\
Company & Need for work \\
& Current workload \\
Competitors & Number of competitors \\
Financial & Expected profitability \\
Market & Overall economy \\
Risk & Expected risk \\
\hline
\end{tabular}

In China, the real estate companies would compete in land auctions which are launched by the government. Generally, in land auctions, the land auction's winner is the bidder who bids at the highest price. If a real estate company gains the land from the auction, the real estate company will select one or more construction companies to complete the building on the land by providing funds and other necessaries. Usually the selections of construction company for a real estate company should consider not only the bidding price but also the construction quality, the construction time and the construction company's reputation, and other more. Such bidding process is usually com- 
pleted by comprehensive evaluations rather than auctions. In this sense, the ultimate evaluating standards of a land auction is usually simpler than that of the construction bidding.

Considering the key common factors for both the real estate company and the construction company bidding, the factors in Table 1 can also be used to forecast the bidding decision for a real estate company in land auction. Both the real estate company and the construction company would consider project size which would influence the profit and risk. Meanwhile, the company's workload and experience would influence the bidding decision of both the real estate company and the construction company. Furthermore, the market is a key factor both in estate company's bidding decision and construction company's bidding decision.

Furthermore, there are some other factors which would influence the bidding decision in a land auction for the real estate company. In China, the real estate companies are faced with increasing risk for the extremely high land price and strict land auction policy. Thus, the real estate companies are under pressure and take risk because of the high demand for development funds. Once the cash flow chain is broken, the real estate company would be faced with threat of bankruptcy. In fact, for a real estate company, the predicted development time of project would influence the predicted recovery of funds and thus influence the financial risk that the real estate company would be faced with. If the predicted development time is short, the real estate company would recover the funds in a short time which could reduce the financial risk, while long development time would lead to high financial risk. Just as Table 1 has listed, expected risk is an important factor in land bidding decision. Thus, in China, the predicted development time for the project would also influence the real estate company's bidding decision.

These factors can be divided into two categories which are numerical factors (such as the estimating profit, necessary development time, competitors number etc.) and non-numerical factors (such as the expected risk). The numerical factors would be considered in the models and the non-numerical factors would be considered as the bidder's risk preference and attitude which is described in prospect theory. Actually, attributes of the land auctions are influential factors. The auctions considering the influential factors are called as multiattribute auctions. With the above analysis, we argue that the factors in Table 1 in addition to the predicted development time can be applied to a real estate company's bidding decisions. Such influential factors are applied to the multi-attribute additive utility in the third generation of prospect theory.

In these factors, project size, need for work, number of competitors, expected profitability and predicted development time are numerical factors, while experience for similar project, overall economy and expected risk are non-numerical factors. In the numerical factors, expected profitability and predicted development time are attributes in our models. Project size also can be seen as an attribute in our models. Actually, project size can be reflected in predicted profit and predicted development time. Thus in our case study, we would not discuss the influence of project size independently though it is an attribute in our models. Similarly, need for work would also influence the predicted project profit and time and can be seen as an attribute in our models. However, we wouldn't consider it independently in our case study. In addition, number of competitors would influence the probability of obtaining the land at a certain bidding price though it isn't an attribute in our models. As to non-numerical factors, experience for similar project would influence the expected risk which would be considered in prospect theory as well in our models. Finally, the overall economy would influence the predicted profit and expected risk, both of which would be considered in our models.

\subsection{Analysis of simultaneous auctions}

Simultaneous auctions mean that the two auctions are available at the same moment. Meanwhile, all the bidders do not know the other participants' bidding prices. That is to say, the auctions here are the first-price sealed auctions. Then the decisionmaker should make the bidding prices for both of the auctions at the same time without knowing the outcomes of the auctions and other participants' bidding prices. And the optimal bidding price is restricted by the available funds. Meanwhile the optimal bidding prices are determined by the values of the auctions.

To be convenient, we here refer to the first land and the second land as land 1 and land 2 respectively. Since the numbers of participants competing in these two auctions have been known by all of the participants, $n_{1}$ and $n_{2}$ represent the amount of participants competing in auctions of land 1 and land 2 respectively. Bidding prices for land 1 satisfy probability density function $f_{1}$, and 
bidding prices for land 2 satisfy probability density function $f_{2}$. The distribution function of $f_{1}$ is $F_{1}$. And the distribution function of $f_{2}$ is $F_{2}$.

Here the price measuring unit is million dollars. And the time measuring unit is month. In China, the government selects the bidder with the highest bidding price as the winner of the auction. We have noticed some land auctions in China set a highest price bound, and the the bidding price above such bound regarded as invalid. This can avoid the increase of house prices. In this paper, we suppose the bidding prices are all below the highest price. Thus all the bidding prices are valid.

For land 1 , there are $n$ states, denoted as $s_{k}$, $k=1, \ldots, n$. And we set $s_{n}$ as the failure state in which the company fails to obtain land 1 in the first auction. Similarly, for land 2, there are $m$ states, denoted as $s_{k}{ }^{\prime}, k=1, \ldots, m$. Meanwhile we set $s_{m}$ as the failure state in which the company fails to obtain land 2 in the second auction.

Each state involves $\alpha$ attributes which can be denoted as $l, l=1, \ldots, \alpha$ In fact, every attribute is a numerical factor which would influence the bidder's bidding price.

We denote $x_{1}$ as this company's bidding price for land 1 and $x_{2}$ for land 2. Other information is as follows:

$V_{1}$ denotes the value that the company can obtain from land 1. $V_{2}$ denotes the value that the company can obtain from land 2. $R_{1}$ denotes the reference point for land 1 .

$R_{2}$ denotes the reference point for land 2 .

$\lambda_{l}$ denotes the loss aversion coefficient for attribute $v_{l}, l=1, \ldots, \alpha$.

$u_{l}$ is the utility function for attribute $v$ of land $1, l=1, \ldots$, a. $u_{l}^{\prime}$ is the utility function for attribute $v$ of land $2, l=1, \ldots, \alpha$.

$\pi_{\rho_{l}^{(.) l} \text { and }}^{+} \pi_{\rho_{l}^{(.) l}}^{-}$are the decision weights for gains and losses for attribute $v_{l}$ of land $1, l=1, \ldots, \alpha$. $\pi_{\rho_{l}^{(.) l}}^{+}$and $\pi_{\rho_{l}^{(.) l}}^{\prime}$ are the decision weights for gains and losses for attribute $v_{l}$ of land $2, l=1, \ldots, \alpha$. $w_{l}^{+}$and $w_{l}^{-}$are the weighting functions for gains and losses for attribute $v_{l}$ of land $1, l=1, \ldots, \alpha$. $w_{l}^{\prime}+$ and $w_{l}^{\prime-}$ are the weighting functions for gains and losses for attribute $v_{l}$ of land $2, . l=1, \ldots, \alpha$.

$p_{k}$ is the probability of state $s_{k}$ for land 1 . The probability of winning land 1 is $F_{1}^{n_{1}-1}\left(x_{1}\right)$, and the probability of the state $s_{k}$ if land 1 has been obtained is $1 /(n-1)$. Thus $p_{k}=(1 /(n-1)) F_{1}^{n_{1}-1}\left(x_{1}\right), k=$ $1, \ldots, n-1$, while $p_{n}=1-F_{1}^{n_{1}-1}\left(x_{1}\right)$.

$p_{k}{ }^{\prime}$ is the probability of state $s_{k}{ }^{\prime}$ for land 2 . The probability of winning land 2 is $F_{2}^{n_{2}-1}\left(x_{2}\right)$, and the probability of the state $s_{k}{ }^{\prime}$ if land 2 has been obtained is $1 /(m-1)$. Thus $p_{k}=(1 /(m-1)) F_{2}^{n_{2}-1}\left(x_{2}\right), k=1$,
.., $m-1$ while $p_{m}=1-F_{2}^{n_{2}-1}\left(x_{2}\right)$.

The first situation we will solve is the one that the first land auction and the second land auction are available at the same moment and the company would decide the bidding prices for both of the two auctions at this moment with a limited funds.

The values here can be obtained from (6) which involves additive utility function in CPT. Considering the states $s_{k}$ for land 1 , we can obtain the value of land 1 :

$$
\begin{aligned}
V_{1}= & \sum_{l=1}^{\alpha} \sum_{j=1}^{k_{l}} \pi_{\rho_{l}^{(j) l}}^{+} u_{l}\left(f(s)_{\rho_{l}^{(j) l}}\right)+ \\
& \sum_{l=1}^{\alpha} \sum_{j=k_{l}+1}^{n} \pi_{\rho_{l}^{(j) l}}^{-} u_{l}\left(f(s)_{\rho_{l}^{(j) l}}\right) .
\end{aligned}
$$

Considering the states $s_{k}$ for land 2 , we can obtain the value of land 2 :

$$
\begin{aligned}
V_{2}= & \sum_{l=1}^{\alpha} \sum_{j=1}^{k_{l}^{\prime}} \pi_{\rho_{l}^{(j) l}}^{+} u_{l}^{\prime}\left(f(s)_{\rho_{l}^{(j) l}}\right)+ \\
& \sum_{l=1}^{\alpha} \sum_{j=k_{l}^{\prime}+1}^{m} \pi_{\rho_{l}^{\prime}-}^{\prime(j) l} u_{l}^{\prime}\left(f(s)_{\rho_{l}^{(j) l}}\right)
\end{aligned}
$$

with:

$$
\begin{aligned}
& \pi_{\rho_{l}^{(j) l}}^{+}=w_{l}^{+}\left(\rho_{l}^{(1)}, \ldots, \rho_{l}^{(j)}\right)-w_{l}^{+}\left(\rho_{l}^{(1)}, \ldots, \rho_{l}^{(j-1)}\right), \\
& l=1,2, \ldots, \alpha ; \\
& \pi_{\rho_{l}^{(j) l}}^{-}=w_{l}^{-}\left(\rho_{l}^{(j)}, \ldots, \rho_{l}^{(n)}\right)-w_{l}^{-}\left(\rho_{l}^{(j+1)}, \ldots, \rho_{l}^{(n)}\right), \\
& l=1,2, \ldots, \alpha ; \\
& \pi_{\rho_{l}^{(j) l}}^{\prime+}=w_{l}^{\prime}\left(\rho_{l}^{(1)}, \ldots, \rho_{l}^{(j)}\right)-w_{l}^{\prime+}\left(\rho_{l}^{(1)}, \ldots, \rho_{l}^{(j-1)}\right), \\
& l=1,2, \ldots, \alpha ; \\
& \pi_{\rho_{l}^{(j) l}}^{\prime}=w_{l}^{\prime}\left(\rho_{l}^{(j)}, \ldots, \rho_{l}^{(n)}\right)-w_{l}^{\prime}\left(\rho_{l}^{(j+1)}, \ldots, \rho_{l}^{(n)}\right), \\
& l=1,2, \ldots, \alpha .
\end{aligned}
$$

Thus the decision-maker would choose the optimal $x_{1}$ and $x_{2}$ at which the valuation of $V_{1}+V_{2}$ hits the largest.

Notice that the ranking of outcomes on a certain attribute has no relationship with the ranking of outcomes on the other attribute. Furthermore, the ranking of outcomes about land 1 has no connection to the ranking of outcomes about land 2 . Optimal $x_{1}$ and $x_{2}$ reflect the optimal bidding price that the bidder would offer for land 1 and land 2 . Because in optimal $x_{1}$ and $x_{2}$, the bidder would get the largest value from these two auctions.

This model could be extended to more than two land auctions. For the $n t h$ land auction $n>2$, the value $V_{n}$ can be described as: 


$$
\begin{aligned}
V_{n}= & \sum_{l=1}^{\alpha} \sum_{j=1}^{k_{l}^{(n)}} \pi_{\rho_{l}^{(j) l}}^{(n)+} u_{l}^{(n)}\left(f(s) \rho_{l}^{(j) l}\right)+ \\
& \sum_{l=1}^{\alpha} \sum_{j=k_{l}^{(n)}+1}^{m} \pi_{\rho_{l}^{(j) l}}^{(n)-} u_{l}^{(n)}\left(f(s) \rho_{l}^{(j) l}\right)
\end{aligned}
$$

with:

$$
\begin{aligned}
& \pi_{\rho_{l}^{(j) l}}^{(n)+}=w_{l}^{(n)+}\left(\rho_{l}^{(1)}, \ldots, \rho_{l}^{(j)}\right)- \\
& w_{l}^{(n)+}\left(\rho_{l}^{(1)}, \ldots, \rho_{l}^{(j-1)}\right), l=1,2, \ldots, \alpha, \\
& \pi_{\rho_{l}^{(j) l}}^{(n)-}=w_{l}^{(n)-}\left(\rho_{l}^{(j)}, \ldots, \rho_{l}^{(n)}\right)- \\
& w_{l}^{(n)-}\left(\rho_{l}^{(j+1)}, \ldots, \rho_{l}^{(n)}\right), l=1,2, \ldots, \alpha .
\end{aligned}
$$

Then the decision-maker would choose the optimal $x_{1}, x_{2}, \ldots x_{n}$ for land 1 , land $2, \ldots$, land $n$, at which the valuation of $V_{1}+V_{2}+\ldots+V_{n}$ hits the largest.

\subsection{Analysis of time-sequential auctions}

Time-sequential auctions mean that the two auctions are available at different time. The second auction is proposed after the first auction has been sold but before the development outcome of the first auction is known. And the available money is not enough to support the bidder to participant in the second land auction. In this situation, the decision-maker has to decide whether to exchange the first auction for the second or not.

In this situation the decision-maker would decide the acceptable price to abandon the first auction. That is to say, the WTA (willingness-toaccept) valuation of the first auction should be determined. The WTA valuation is the increment wealth such that the owner of land 1 is indifferent between retaining it and giving up it in exchange for the certainty of that increment (Schmidt et al. 2008).

Before we obtain the WTA value of the first auction, we should firstly calculate the optimal bidding price $x_{1}^{*}$ for land 1 and we suppose at this price the company has won the first land. According to (12), we can obtain the optimal $x_{1}^{*}$. Thus $x_{1}^{*}$ is the valuation of $x_{1}$ that makes $V_{1}$ hit the largest value.

In this situation, the bidder is considering whether to give up land 1 , and then the first problem is the lowest selling price of land 1 which the company is willing to accept.
The WTA valuation of land 1 , denoted as $z_{c l}$, is the increment wealth such that the owner of land 1 is indifferent between retaining it and giving up it in exchange for the certainty of that increment. The reference act, denoted as $h$, is the act of holding land 1 . Accordingly, we define $z_{c l}$ as the certain payoff of some constant act $g$ defined such that $V_{1}(g, h)=0$.

Note that the traditional WTA valuation only takes one attribute into account, which is monetary outcome. However, it is worth noting that in this paper a attributes are considered when calculating WTA valuation.

To avoid directly solving the problem that whether the company would abandon land 1 and rebid for land 2, we turn now to another problem that at which bidding price for land 2 the company would obtain the maximum value if the company has decided to exchange land 1 for land 2 .

In order to solve this decision problem, we now study additive utility functions in PT3 which involves multi-attribute decision problems and takes exchanging decision into consideration. In fact, additive utility function in PT3 can be obtained from the extension of the additive function in CPT.

Based on the additive utility function in CPT, now we try to acquire additive utility function in PT3.

The reason why additive utility function in PT3 needs to be deduced is that it can help us to analyze the participants' bidding strategies when the outcome of the first land is uncertain. That is to say, in this situation the real estate company has been endowed with the first land, however the outcome of the first land development project is under uncertainty. At this moment another land auction is available to the public. And we would study on whether this company will give up the first land and rebid for the second land since the company's available funds are limited.

According to PT3 and the additive utility in CPT, we can obtain additive utility in PT3:

$$
\begin{aligned}
& P T 3(f, h)=\sum_{l=1}^{\alpha} \sum_{j=1}^{k_{l}} \pi_{\rho_{l}^{(j) l}}^{+} u_{l}[f(s)-h(s)] \rho_{l}^{(j) l}+ \\
& \sum_{l=1}^{\alpha} \sum_{j=k_{l}+1}^{n} \pi_{\rho_{l}^{(j) l}}^{-} u_{l}[f(s)-h(s)]_{\rho_{l}^{(j) l}}
\end{aligned}
$$

with

$$
\begin{aligned}
& \pi_{\rho_{l}^{(j) l}}^{+}=w_{l}^{+}\left(\rho_{l}^{(1)}, \ldots, \rho_{l}^{(j)}\right)-w_{l}^{+}\left(\rho_{l}^{(1)}, \ldots, \rho_{l}^{(j-1)}\right) \\
& l=1, \ldots, \alpha
\end{aligned}
$$




$$
\begin{aligned}
& \pi_{\rho_{l}^{(j) l}}^{-}=w_{l}^{-}\left(\rho_{l}^{(j)}, \ldots, \rho_{l}^{(n)}\right)-w_{l}^{-}\left(\rho_{l}^{(j+1)}, \ldots, \rho_{l}^{(n)}\right), \\
& l=1, \ldots, \alpha .
\end{aligned}
$$

For each $f(s)-h(s)$, there exist permutations $\rho_{l}$ for attribute $v_{l}, l=1, \ldots, \alpha$, such that $\rho_{l}$ satisfies $\left[f\left(s_{\rho_{l}^{(1) l}}\right)-h\left(s_{\left.\rho_{l}^{(1) l}\right)}\right)\right]>\ldots>\left[f\left(s_{\rho_{l}^{(n) l}}\right)-h\left(s_{\rho_{l}^{(n) l}}\right)\right]$. As a matter of convenience, we write $[f(s)-h(s)]_{\rho_{l}^{(j) l}}$ instead of $\left[f\left(s_{\rho_{l}^{(j) l}}\right)-h\left(s_{\rho_{l}^{(j) l}}\right)\right]$. In this formula, $[f(s)-h(s)]_{\rho_{l}^{(j) l}}$ denotes the $l$-th attribute of the outcome which is obtained under state $j$ with act $f$ substituting for reference act $h$.

The function $u_{l}$ is strictly increasing and continuous satisfying $u_{l}\left(f\left(s_{j}\right)-h\left(s_{j}\right)\right)=0$ if the attribute $v_{l}$ of the outcome that is obtained under state $j$ with act $f$ is equal to the attribute $v_{l}$ obtained under the same state with act $h$. The decision weights $\pi^{+}()$. and $\pi_{\rho_{l}^{(.) l}}^{-}$are the decision weights for gains and losses for attribute $v_{l}, l=1, \ldots, \alpha . w_{l}^{+}$and $w_{l}^{-}$are the weighting functions for gains and losses for attribute $v_{l}, l=1,2, \ldots, \alpha$.

Additive utility function in PT3 extends the additive utility function in CPT. By additive utility function in PT3, we can analyze exchanging decision in auctions which involve more than one attribute.

Many decision situations involve outcomes that consist of several attributes. In applied decision analysis, it is useful to decompose the utility function over these multi-attribute outcomes into separate utility functions over the different attributes to reduce the number of preference elicitation. This is only justified if the decision-maker's preferences satisfy particular assumptions. In this paper, we propose additive utility function under PT3. And we apply additive utility function to decision of bidding problem which is more general for solving decision problems without particular assumption.

Then we turn to the application of additive utility function in PT3 in land auctions. At the moment the real estate company is endowed with land 1 and the company treats this as her reference act, denoted as act $h$.

However, the company is now offered with the opportunity to sell land 1 and rebid for land 2 . We denote the act of selling land 1 and rebidding for land 2 as act $f$. Suppose there are $n$ states for land 1 in the future if it is hold by the company and $m$ natural states for land 2 in the future if the company decides to rebid for land 2 at the bidding price $x_{2}^{*}$. Thus we can get $n \times m$ states denoted as $\operatorname{Si}(i=1$, $\ldots, n \times m)$ when both land 1 and land 2 are considered simultaneously. $P i$ is denoted as the probability of state $S i$.
If the company obtains land 2 when rebidding it at the bidding price $x_{2}^{*}$, then the probability of this state is $1 / n \times F_{2}^{n_{2}-1}\left(x_{2}^{*}\right)$. If the company fails to obtain land 2 when rebidding it at the bidding price $x_{2}^{*}$, then the probability of this state is $1 / n \times\left(1-F_{2}^{n_{2}-1}\left(x_{2}^{*}\right)\right)$. Then with additive utility under PT3, we are able to obtain the optimal valuation of $P T 3(f, h)$.

The last step is to compare the optimal valuation of $P T 3(f, h)$ and zero. If the former is larger than zero, which means that the act $f$ has a larger value relative to the reference act $h$, then the company would exchange land 1 for land 2. Otherwise, the company would hold land 1.

This model can also be extended to $n$ land auctions, $n>2$. Suppose $n=3$, which means before the third land auction is proposed, two land auctions have been obtained, however, the real estate company doesn't known the outcomes of development. Thus, the real estate company is faced with four choices. The first is holding land 1 and land 2. The second is selling land 1 to rebid for land 3 while holding land 2. The third choice is selling land 2 to rebid for land 3 while holding land 1 . The last choice is selling both of land 1 and land 2 to rebid for land 3 . We can define the following acts.

$f_{1}$ : holding land 1 and land 2.

$f_{2}$ : selling land 1 to rebid for land 3 while holding land 2.

$f_{3}$ : selling land 2 to rebid for land 3 while holding land 1.

$f_{4}$ : selling both of land 1 and land 2 to rebid for land 3.

Let act $f_{1}$ as the reference act. Then with the same method, which has been said above, we can obtain the optimal valuations of $P T 3\left(f_{2}, f_{1}\right), P T 3$ $\left(f_{3}, f_{1}\right), P T 3\left(f_{4}, f_{1}\right)$.

After we obtain the optimal valuations of $\operatorname{PT} 3\left(f_{2}, f_{1}\right), \operatorname{PT} 3\left(f_{3}, f_{1}\right), \operatorname{PT} 3\left(f_{4}, f_{1}\right)$, we can compare the valuations so that we can predict the choice of the developer. For example, if $\operatorname{PT} 3\left(f_{4}, f_{1}\right)>0$, it means when the real estate developer considers land 1, land 2 and land 3 simultaneously, the developer is predicted to choose act $f_{4}$ rather than $f_{1}$. However, if $P T 3\left(f_{4}, f_{1}\right)>0$, the developer is predicted to sell both of land 1 and land 2 to rebid for land 3 . With the similar method, we can analyze and predict the developer's possible choice.

When $n>3$, with the same analysis process, we can predict the developer's possible choice. But the developer will face $2^{n-1}$ choices, these combination choices will become a computational bottleneck when the number of land $n$ is some large. Considering that each land auction needs a huge amount of funds, and the large number of land auctions rarely happens in practice, we will not discuss this in more details. 


\subsection{Analysis of event-sequential auctions}

Event-sequential auctions mean that the four auctions are available at different time. However, the forth auction is proposed after the outcomes of the previous three auctions have been known. In this situation, the bidding price for the last auction should be determined. And now we will explain the optimal bidding price for the forth auction from the aspect of the reference point prediction.

A mathematical understanding of how reference points evolve may help predict the happiness or satisfaction experienced while a sequence of variable outcomes unfold. In terms of auctions, there are always more than one auction for bid. Furthermore the previous auctions' outcomes would have influence on the future bidding strategy. Now we try to interpret this influence from the aspect of reference point.

We have stated the prediction of reference point proposed by Baucells et al. (2011) which is mainly for the stock price in finance market. The reference point is determined by three factors: the built-in profit $r$, weighting function and the value of $y$.

However, in this paper, there are several differences from Baucells et al. (2011) while considering the prediction of the reference point. More specifically, we will try to interpret the reference point predicting formula in bidding decisions. In this situation, the real estate development company has received several pieces of land. Furthermore, this company has completed some of the development projects and has obtained the ultimate profits for these projects. We would discuss the influence that the previous profits would make on the company's bidding price for the forthcoming land auction.

From the reference formula, we can see the built-in profit $r$ which is interpreted as expectation about the future. However, in our situation, $r$ reflects the real estate development company's expectation to the next land without consideration of the profits which the company has gained from the previous land development. And $y$ reflects the profit that the company has gained from the previous land development projects. The weight is decided by the ordering of the profit. That is to say, both the largest profit and the smallest profit have a strong and significant effect on the prediction of reference point, which corresponds to reality and is understandable. And as the outcomes considered in this paper are of a attributes so in this paper, we can decompose $y_{j}$ into $y_{l j}$ for attribute $v_{l}, l=$ $1,2, \ldots$, a. Then we rank the valuations of $y_{l j}, j=$ $1, \ldots, n$, for attribute $v_{l}, l=1,2, \ldots, \alpha$, as the se- quence: $y_{l(1)}, y_{l(2)}, \ldots, y_{l(\mathrm{n})}$, from the biggest valuation to the smallest. And as the outcomes considered in this paper are of a attributes, we can get a reference points in a attributes respectively. $r_{n+1, l}$ is denoted as the reference point for attribute $v_{l}$ for the $n+1$ th land. $w_{r_{n+1, l}}$ is denoted as the weighting function for the prediction of $r_{n+1, l} . \mathrm{r}$ can be decomposed into $\rho_{l}, l=1,2, \ldots, \alpha$.

Thus, the predicting formulas in auctions are similar to the one of Baucells et al. (2011). Nevertheless some differences still exist. The predicting formulas can be depicted as:

$$
\begin{aligned}
r_{n+1, l}= & \rho_{l}+\sum_{j=1}^{n}\left[w_{r_{n+1, l}}(j / n)-\right. \\
& \left.w_{r_{n+1, l}}((j-1) / n)\right] y_{l(j) .}
\end{aligned}
$$

We utilize the formulas to predict the reference points when the bidder is prepared to bid for the upcoming land auction after gaining profits from the previous development projects. Once we have known the reference point for the upcoming land auction, we would be able to get the optimal bidding price for the upcoming land auction.

We have analyzed these three situations. In the simultaneous auctions, additive utility functions in CPT are adopted. While in time-sequential auctions, additive utility functions in PT3 are used. Meanwhile, in event-sequential auctions, predictions of reference point are applied.

In the following sections, we will solve these three situations with more details. And we will try to explain our methods through the following three concrete cases.

\section{CASE STUDY}

\subsection{Background}

Currently there are two plots of land, both of which are profitable for the developers. A real estate development company is now competing in these two auctions of land. This company would make a rational and scientific bidding strategy, from which this company would acquire maximum value. The available fund a company is limited. At present this company is able to afford 50 million dollars. Thus the manager of this company would decide the bidding prices for both of the two land auctions. Although we have given description of the factors that would influence the bidding decision and discussed the bidding decisions which involve several attributes in Section 4, in this section two land auction attributes the profit and the development 
Table 2. Two land auctions

\begin{tabular}{lll}
\hline (Item) & land 1 & land 2 \\
\hline Project & Housing project & Housing Project \\
& Total floor area 68093 square meters & Total floor area 56554 square meters \\
& Basement area 5489 square meters & Basement area 4236 square meters \\
Location & Bingjiang Zone, Hangzhou city, China & Yuhang Zone, Hangzhou city, China \\
Competitor number & 10 & 5 \\
Bidding system & Open competitive bid & Open competitive bid \\
Fund & self and bank & self and bank \\
Product & high-end or low-end & high-end or low-end \\
\hline
\end{tabular}

time, are discussed. They are the two main factors that influence the land bidding decision. Table 2 presents the main information of the two actual land auctions.

Before the company submits its bidding prices for both of land auctions, future profit and necessary development time for these two pieces of land have been analyzed and predicted with scientific methods. Obviously, a piece of land with less time and more predicted profit is much more beneficial to the company. However there exists risk because of the uncertainties of the product type (high-end or low-end), government policy, weather, market requirement, labor market supply and market competition et al. That is to say, the company could just predict certain outcomes with corresponding probabilities rather than certainty. Generally, a real estate company would do some predictions about the land's cost, profit, and the possible development time before it participates in the land auctions. For different product types, the company would predict different profit and development time as the most possible profit and development time, respectively. Actually, if the company would develop high-end houses on the land, then the development time would be longer and the estimated profit would be higher, while if the product type is low-end, then the time would be shorter and the profit would be lower. Thus, if the company can obtain these two plots of land then for each land the company would predict two states.

According to the company's research on the participants' previous bidding decision, the company can get the probability density functions $\varphi_{1}$ and $\varphi_{2}$ which are as follows:

$$
\begin{aligned}
& \varphi_{1}(x)= \begin{cases}2.5 \times 10^{-3} x & \text { if } 0 \leqslant x \leqslant 20 \\
-2.5 \times 10^{-3} x+0.1 & \text { if } 20 \leqslant x \leqslant 40\end{cases} \\
& \varphi_{2}(x)= \begin{cases}0.01 x & \text { if } 0 \leqslant x \leqslant 10 \\
-0.01 x+0.2 & \text { if } 10 \leqslant x \leqslant 20^{\circ}\end{cases}
\end{aligned}
$$

Obviously, from the expressions, we can see $\varphi_{1}$ and $\varphi_{2}$ are symmetric functions, which is intelligible for the common sense that few of the participants will bid quite low or quite high prices while most of them are medium prices. We can then obtain the probability distribution functions $F_{1}(x)$ and $F 2(x)$, which are described as follows:

$$
\begin{aligned}
& F_{1}(x)=\left\{\begin{array}{l}
1.25 \times 10^{-3} x^{2} \\
-1.25 \times 10^{-3} x^{2}+0.1 x-1
\end{array}\right. \\
& \text { if } 0 \leqslant x \leqslant 20 \\
& \text { if } 20 \leqslant x \leqslant 40 \\
& F_{2}(x)=\left\{\begin{array}{l}
0.005 x^{2} \\
-0.005 x^{2}+0.2 x-1
\end{array}\right. \\
& \text { if } 0 \leqslant x \leqslant 10 \\
& \text { if } 10 \leqslant x \leqslant 20
\end{aligned}
$$

As we have stated above, if the company can obtain these two plots of land then for each land the company would predict two states. Thus for land 1, there are three states, denoted as $s_{1}, s_{2}$, $s_{3}$ respectively. $s_{1}$ and $s_{2}$ represent two different states for two different product types and $s_{3}$ represents that the company loses the land auction. Similarly, for land 2, there are also three states, denoted as $s_{1}{ }^{\prime}, s_{2}{ }^{\prime}, s_{3}{ }^{\prime}$ respectively. And here we set $R_{1}$ as (30 months, 0 ), while $R_{2}$ (15 months, 0$)$. Also we suppose the valuations of the second attribute (i.e. profit) in all the states are not less than 0 .

Briefly, here we adopt the utility function and probability weighting function in cumulative prospect theory, both for the first attribute and the second attribute. Nonetheless, the parameters in the functions are not the same for the first attribute and the second attribute. Here we suppose that parameters of $u_{1}$ and $w_{1}$ are obtained from Tversky and Kahneman (1992), while parameters of $u_{2}$ and $w_{2}$ are obtained from Abdellaoui (2000) which has the similar approach to Cheng et al. 2011. We set $u_{1}{ }^{\prime}, u_{2}{ }^{\prime}, w_{1}{ }^{\prime}, w_{2}{ }^{\prime}$ satisfying: $u_{1}{ }^{\prime}=u_{1}, u_{2}{ }^{\prime}=u_{2}, w_{1}{ }^{\prime}=$ $w_{1}, w_{2}^{\prime}=w_{2}$ : 


$$
\begin{aligned}
& u_{1}(x)=\left\{\begin{array}{ll}
x^{0.88} & \text { if } x \geqslant 0 \\
-2.25(-x)^{0.88} & \text { if } x<0
\end{array},\right. \\
& w_{1}(p)=\left\{\begin{array}{l}
w_{1}^{+}(p)=p^{0.61} /\left(p^{0.61}+(1-p)^{0.61}\right)^{0.61} \\
w_{1}^{-}(p)=p^{0.69} /\left(p^{0.69}+(1-p)^{0.69}\right)^{0.69}
\end{array}\right. \\
& u_{2}(x)= \begin{cases}x^{0.89} & \text { if } x \geqslant 0 \\
-2.25(-x)^{0.92} & \text { if } x<0\end{cases} \\
& w_{2}(p)=\left\{\begin{array}{l}
w_{2}^{+}(p)=p^{0.6} /\left(p^{0.6}+(1-p)^{0.6}\right)^{0.6} \\
w_{2}^{-}(p)=p^{0.7} /\left(p^{0.7}+(1-p)^{0.7}\right)^{0.7}
\end{array}\right.
\end{aligned}
$$

\subsection{Simultaneous auctions}

We set the limited fund as 50 million dollars. Thus $x_{1}+x_{2} £ 50$. Each state of land 1 and land 2 can be described as follows.

land 1:

(1) $s_{1}$ : (time, profit $)=\left(25\right.$ months, $\left.30-x_{1}\right)$;

$p_{1}=p\left(s_{1}\right)=0.5 F_{1}^{9}\left(x_{1}\right)$,

(2) $s_{2}$ : (time, profit) $=\left(35\right.$ months, $\left.10-x_{1}\right)$;

$p_{2}=p\left(s_{2}\right)=0.5 F_{1}^{9}\left(x_{1}\right)$

(3) $s_{3}$ : (time, profit) $=(0,0)$;

$p_{3}=p\left(s_{3}\right)=1-F_{1}^{9}\left(x_{1}\right)$.

land 2 :

(1) $s_{1}{ }^{\prime}$ : (time, profit $)=\left(15\right.$ months, $\left.25-x_{2}\right)$;

$p_{1}^{\prime}=p\left(s_{1}^{\prime}\right)=0.5 F_{2}^{4}\left(x_{2}\right)$;

(2) $s_{2}{ }^{\prime}$ : (time, profit $)=\left(20\right.$ months, $\left.20-x_{2}\right)$;

$p_{2}^{\prime}=p\left(s_{2}^{\prime}\right)=0.5 F_{2}^{4}\left(x_{2}\right)$

(3) $s_{3}{ }^{\prime}$ : (time, profit) $=(0,0)$;

$p_{3}^{\prime}=p\left(s_{3}^{\prime}\right)=1-F_{2}^{4}\left(x_{2}\right)$.

With additive utility under CPT, we are able to obtain the utilities of land 1 and land 2, which we are denoted as $V_{1}$ and $V_{2}$ :

$$
\begin{aligned}
& V_{1}=\pi_{1}^{+}\left(p_{1}\right) u_{1}(5)+\pi_{1}^{-}\left(p_{2}\right) u_{1}(-5)+ \\
& \pi_{1}^{+}\left(p_{3}\right) u_{1}(30)+\pi_{2}^{+}\left(p_{1}\right) u_{2}\left(30-x_{1}\right)+ \\
& \pi_{2}^{+}\left(p_{1}\right) u_{2}\left(10-x_{1}\right), \\
& V_{2}=\pi_{1}^{-}\left(p_{2}\right) u_{1}(-5)+\pi_{1}^{+}\left(p_{3}^{\prime}\right) u_{1}(15)+ \\
& \pi_{2}^{+}\left(p_{1}^{\prime}\right) u_{2}\left(25-x_{2}\right)+\pi_{2}^{+}\left(p_{2}^{\prime}\right) u_{2}\left(20-x_{2}\right) .
\end{aligned}
$$

Then the company would make a decision of $x_{1}$ and $x_{2}$, which can give the company the maximum valuation of $V_{1}+V_{2}$. And it can be predicted by the following optimization problem with the constraints that the profits of all states are not less than 0 :

$$
\begin{array}{ll}
\max & V=V_{1}+V_{2} \\
\text { s.t. } & x_{1}+x_{2} \leq 50 \\
& 30-x_{1} \geq 0 \\
& 10-x_{1} \geq 0 \\
& 25-x_{2} \geq 0
\end{array}
$$

$$
\begin{aligned}
& 20-x_{2} \geq 0 \\
& x_{1}, x_{2} \geq 0 .
\end{aligned}
$$

According to the ranking of the outcomes of land 1 on the first attribute, we can get:

$$
\begin{aligned}
& \pi_{1}^{+}\left(p_{1}\right)=w_{1}^{+}\left(p_{1}+p_{3}\right)-w_{1}^{+}\left(p_{3}\right)= \\
& w_{1}^{+}\left(0.5 F_{1}^{9}\left(x_{1}\right)+\left(1-F_{1}^{9}\left(x_{1}\right)\right)\right)- \\
& w_{1}^{+}\left(1-F_{1}^{9}\left(x_{1}\right)\right), \\
& \pi_{1}^{+}\left(p_{3}\right)=w_{1}^{+}\left(p_{3}\right)=w_{1}^{+}\left(\left(1-F_{1}^{9}\left(x_{1}\right)\right)\right), \\
& \pi_{1}^{-}\left(p_{2}\right)=w_{1}^{-}\left(p_{2}\right)=w_{1}^{-}\left(0.5 F_{1}^{9}\left(x_{1}\right)\right) .
\end{aligned}
$$

According to the ranking of the outcomes of land 2 on the first attribute, we can get:

$$
\begin{aligned}
& \pi_{1}^{-}\left(p_{2}^{\prime}\right)=w_{1}^{-}\left(p_{2}^{\prime}\right)=w_{1}^{-}\left(0.5 F_{2}^{4}\left(x_{2}\right)\right) \\
& \pi_{1}^{+}\left(p_{3}^{\prime}\right)=w_{1}^{+}\left(p_{3}^{\prime}\right)=w_{1}^{+}\left(1-F_{2}^{4}\left(x_{2}\right)\right)
\end{aligned}
$$

According to the ranking of the outcomes of land 1 on the second attribute we can get:

$$
\begin{aligned}
& \pi_{2}^{+}\left(p_{1}\right)=w_{2}^{+}\left(p_{1}\right)=w_{2}^{+}\left(0.5 F_{1}^{9}\left(x_{1}\right)\right), \\
& \pi_{2}^{+}\left(p_{2}\right)=w_{2}^{+}\left(p_{1}+p_{2}\right)-w_{2}^{+}\left(p_{1}\right)= \\
& w_{2}^{+}\left(0.5 F_{1}^{9}\left(x_{1}\right)+1-F_{1}^{9}\left(x_{1}\right)\right)-w_{2}^{+}\left(0.5 F_{1}^{9}\left(x_{1}\right)\right) .
\end{aligned}
$$

According to the ranking of the outcomes of land 2 on the second attribute we can get:

$$
\begin{aligned}
& \pi_{2}^{+}\left(p_{1}^{\prime}\right)=w_{2}^{+}\left(p_{1}^{\prime}\right)=w_{2}^{+}\left(0.5 F_{2}^{4}\left(x_{2}\right)\right) \\
& \pi_{2}^{+}\left(p_{2}^{\prime}\right)=w_{2}^{+}\left(p_{1}^{\prime}+p_{2}^{\prime}\right)-w_{2}^{+}\left(p_{1}^{\prime}\right)= \\
& w_{2}^{+}\left(0.5 F_{2}^{4}\left(x_{2}\right)+0.5 F_{2}^{4}\left(x_{2}\right)\right)-w_{2}^{+}\left(0.5 F_{2}^{4}\left(x_{2}\right)\right) .
\end{aligned}
$$

The optimal solution of this problem is $x_{1}{ }^{*}=8.5$, $x_{2}{ }^{*}=10.7$, $\max V_{1}{ }^{*}=19.9471$. This means the company would probably bid for land 1 at 8.5 million dollars and bid for land 2 at 10.7 million dollars, for at these bidding prices the company would obtain the highest value of 30.8025 .

\subsection{Time-sequential auctions}

The situation discussed in this section is independent from the situation discussed in the above section. In this situation, only land 1 is for bid at present. Similarly, the manager would make decision on the bidding price for land 1 . With the additive function in CPT, we can obtain the utility of land 1 (i.e. $V_{1}$ ): 


$$
\begin{aligned}
& V_{1}=\pi_{1}^{+}\left(p_{1}\right) u_{1}(5)+\pi_{1}^{-}\left(p_{2}\right) u_{1}(-5)+ \\
& \pi_{1}^{+}\left(p_{3}\right) u_{1}(30)+\pi_{2}^{+}\left(p_{1}\right) u_{2}\left(30-x_{1}\right)+ \\
& \pi_{2}^{+}\left(p_{2}\right) u_{2}\left(10-x_{1}\right)
\end{aligned}
$$

in which

$$
\begin{aligned}
& \pi_{1}^{+}\left(p_{1}\right)=w_{1}^{+}\left(p_{1}+p_{3}\right)-w_{1}^{+}\left(p_{3}\right)= \\
& w_{1}^{+}\left(0.5 F_{1}^{9}\left(x_{1}\right)+\left(1-F_{1}^{9}\left(x_{1}\right)\right)\right)- \\
& w_{1}^{+}\left(1-F_{1}^{9}\left(x_{1}\right)\right), \\
& \pi_{1}^{+}\left(p_{3}\right)=w_{1}^{+}\left(p_{3}\right)=w_{1}^{+}\left(\left(1-F_{1}^{9}\left(x_{1}\right)\right)\right), \\
& \pi_{1}^{-}\left(p_{2}\right)=w_{1}^{-}\left(p_{2}\right)=w_{1}^{-}\left(0.5 F_{1}^{9}\left(x_{1}\right)\right), \\
& \pi_{2}^{+}\left(p_{1}\right)=w_{2}^{+}\left(p_{1}\right)=w_{2}^{+}\left(0.5 F_{1}^{9}\left(x_{1}\right)\right), \\
& \pi_{2}^{+}\left(p_{2}\right)=w_{2}^{+}\left(p_{1}+p_{2}\right)-w_{2}^{+}\left(p_{1}\right)= \\
& w_{2}^{+}\left(0.5 F_{1}^{9}\left(x_{1}\right)+0.5 F_{1}^{9}\left(x_{1}\right)\right)-w_{2}^{+}\left(0.5 F_{1}^{9}\left(x_{1}\right)\right) .
\end{aligned}
$$

Then we would maximize the valuation of $V_{1}$ with the constraints that the profits in all states are not less than 0 , which can be depicted as the follows:

$$
\begin{array}{ll}
\max & V_{1} \\
\text { s.t. } & 30-x_{1} \geq 0 \\
& 10-x_{1} \geq 0 \\
& 0 \leq x_{1} \leq 50 .
\end{array}
$$

The optimal solution of (27) is $x_{1}{ }^{*}=8.5, V_{1}{ }^{*}=$ 19.9471. This means if there is just land 1 for bid, then the company would probably bid for land 1 at 8.5 million dollars, at which the company would obtain the highest value of 19.9471 from land 1 .

Assume land 1 has been offered to the real estate company at the payment of the bidding price calculated above (i.e. $x_{1}^{*}$ ). That is to say, at the moment the company is endowed with land 1. However, soon after the company won land 1 from the auction, the government announces that land 2 is available. The auction for land 2 is begun now. In this situation, the real estate company is considering whether to give up land 1 and rebid for land 2 for the rest available funds couldn't support the company to bid for land 2 .

Table 3. WTA Valuation of land 1

\begin{tabular}{lll}
\hline & 0.5 & 0.5 \\
\hline$h$ & $\left(25,30-x_{1}^{*}\right)$ & $\left(35,10-x_{1}^{*}\right)$ \\
$g$ & $\left(0, z_{c l}\right)$ & $\left(0, z_{c l}\right)$ \\
\hline
\end{tabular}

The situation is depicted by the following matrix (in which the columns are states, with probabilities shown at the top, the rows are acts, and the entries in the cells are consequences).

According to the definition of WTA valuation, we set $V(g, h)=0$ to get the valuation of $z_{c l}$, i.e. the WTA valuation of land 1 .

$V(g, h)=u_{1}(25-0)\left[w_{1}^{+}(1)-w_{1}^{+}(0.5)\right]+$ $u_{1}(35-0) w_{1}^{+}(0.5)+u_{2}\left(z_{c 1}-30+x_{1}^{*}\right) w_{2}^{-}(0.5)+$ $u_{2}\left(z_{c 1}-10+x_{1}^{*}\right) w_{2}^{+}(0.5)=u_{1}(25)\left[w_{1}^{+}(1)-\right.$ $\left.w_{1}^{+}(0.5)\right]+u_{1}(35) w_{1}^{+}(0.5)+u_{2}\left(z_{c 1}-21.5\right) w_{2}^{-}(0.5)+$ $u_{2}\left(z_{c 1}+1.5\right) w_{2}^{+}(0.5)=0$.

Thus, $z_{c l}=2.86348$. This means the company's lowest acceptable selling price for land 1 is 2.86348 million dollars. Obviously, attribute 1 (time) has influence on the WTA valuation. Therefore, the WTA valuation is unequal to the traditional one in which only one attribute is involved.

There are two natural states for land 1 in the future if it is hold by the company, i.e. (25,30 $\left.x_{1}^{*}\right)$ and $\left(35,10-x_{1}^{*}\right)$. And there are three natural states for land 2 in the future if the company decides to rebid for land 2 at bidding $x_{2}{ }^{*}$, i.e. $(0$, $\left.z_{\mathrm{cl}}\right),\left(15,25+z_{c l}-x_{2}{ }^{*}\right)$ and $\left(20,20+z_{c l}-x_{2}{ }^{*}\right)$. Thus we can get 6 states when both land 1 and land 2 are considered simultaneously. The analysis is described in the Table.

Table 4. Six states of the two land auctions

\begin{tabular}{lllll}
\hline States & $h(\mathrm{Si})$ & $f(\mathrm{Si})$ & $f(\mathrm{Si})-h(\mathrm{Si})$ & $P i$ \\
\hline$S 1$ & $\left(25,30-x_{1}{ }^{*}\right)$ & $\left(0, z_{c l}\right)$ & $(-25,-18.7)$ & $0.5\left(1-F_{2} 4\left(x_{2}{ }^{*}\right)\right)$ \\
$S 2$ & $\left(25,30-x_{1}{ }^{*}\right)$ & $\left(15,25+z_{c l}-x_{2}{ }^{*}\right)$ & $\left(-10,6.3-x_{2}{ }^{*}\right)$ & $0.5 F_{2}{ }^{4}\left(x_{2}{ }^{*}\right) \times 0.5$ \\
$S 3$ & $\left(25,30-x_{1}{ }^{*}\right)$ & $\left(20,20+z_{c l}-x_{2}{ }^{*}\right)$. & $\left(-5,1.3-x_{2}{ }^{*}\right)$ & $0.5 F_{2}{ }^{4}\left(x_{2}{ }^{*}\right) \times 0.5$ \\
$S 4$ & $\left(35,10-x_{1}{ }^{*}\right)$ & $\left(0, z_{\mathrm{cl}}\right)$, & $(-35,-1.3)$ & $0.5\left(1-F_{2}{ }^{4}\left(x_{2}{ }^{*}\right)\right.$ \\
$S 5$ & $\left(35,10-x_{1}{ }^{*}\right)$ & $\left(15,25+z_{c l}-x_{2}{ }^{*}\right)$ & $(-20,26.3-x 2)$ & $0.5 F_{2}{ }^{4}\left(x_{2}{ }^{*}\right) \times 0.5$ \\
$S 6$ & $\left(35,10-x_{1}{ }^{*}\right)$ & $\left(20,20+z_{c l}-x_{2}{ }^{*}\right)$. & $(-15,21.3-x)$ & $0.5 F_{2}{ }^{4}\left(x_{2}{ }^{*}\right) \times 0.5$ \\
\hline
\end{tabular}


State $S 1$ is the composite of $\left(25,30-x_{1}^{*}\right)$ and $\left(0, z_{c l}\right)$ which means that if land 1 is hold the outcome might be $\left(25,30-x_{1}^{*}\right)$, however if land 1 is sold and the company rebids for land 2 the outcome could be $\left(0, z_{c l}\right)$. Similarly, we can explain the rest states from $S 2$ to $S 6$. Note that the profit of land 2 in state $S 1$ and $S 4$ is $z_{c l}$. It is because that if land 1 is sold, the company will obtain $z_{c l}$ equaling to the WTA valuation of land 1 and we suppose that the company would make $x_{2}{ }^{*}$ as her bidding price for land 2. Therefore, if the company fails to acquire land 2 at the bidding price $x_{2}{ }^{*}$, he can still get $z_{c l}$, the price at which he has sold land 1. $x_{1}{ }^{*}$ in the form is the optimal solution we get at the beginning in 5.3. $\left(x_{1}{ }^{*}=8.5\right)$. It means that the company bided for land 1 at $x_{1}{ }^{*} . z_{c l}$ is the valuation we have obtained in 5.3.1 $\left(z_{c l}=2.86348\right)$. And from the table, we can see $x_{2}<26.3$. With additive utility under PT3, we are able to obtain $V(f, h)$. When we rank the valuation of $f(S i)-h(S i)$, the value of $x_{2}{ }^{*}$ will have influence in the ranking of the outcomes in the second attribute. So we would discuss the intervals that $x_{2}{ }^{*}$ might fall into.

When $26.3<x_{2}{ }^{*}<50$,

$$
\begin{aligned}
V(f, h)= & u_{1}(-25)\left[w_{1}^{-}\left(p_{1}+p_{4}\right)-w_{1}^{-}\left(p_{4}\right)\right]+ \\
& u_{1}(-10)\left[w_{1}^{-}\left(p_{1}+p_{2}+p_{4}+p_{5}+p_{6}\right)-w_{1}^{-}\left(p_{1}+p_{4}+p_{5}+p_{6}\right)\right]+ \\
& u_{1}(-5)\left[w_{1}^{-}\left(p_{1}+p_{2}+p_{3}+p_{4}+p_{5}+p_{6}\right)-w_{1}^{-}\left(p_{1}+p_{2}+p_{4}+p_{5}+p_{6}\right)\right]+ \\
& u_{1}(-35) w_{1}^{-}\left(p_{4}\right)+ \\
& u_{1}(-20)\left[w_{1}^{-}\left(p_{1}+p_{4}+p_{5}\right)-w_{1}-\left(p_{1}+p_{4}\right)\right]+ \\
& u_{1}(-15)\left[w_{1}-\left(p_{1}+p_{4}+p_{5}+p_{6}\right)-w_{1}^{-}\left(p_{1}+p_{4}+p_{5}\right)\right]+ \\
& u_{2}\left(1.3-x_{2}\right) w_{2}^{-}\left(p_{3}\right)+ \\
& u_{2}\left(6.3-x_{2}\right)\left[w_{2}^{-}\left(p_{2}+p_{3}\right)-w_{2}^{-}\left(p_{3}\right)\right]+ \\
& u_{2}(-18.7)\left[w_{2}^{-}\left(p_{2}+p_{3}+p_{1}\right)-w_{2}^{-}\left(p_{2}+p_{3}\right)\right]+ \\
& u_{2}\left(21.3-x_{2}^{*}\right)\left[w_{2}^{-}\left(p_{2}+p_{3}+p_{1}+p_{6}\right)-w_{2}^{-}\left(p_{2}+p_{3}+p_{1}\right)\right]+ \\
& u_{2}\left(26.3-x_{2}^{*}\right)\left[w_{2}^{-}\left(p_{1}+p_{2}+p_{3}+p_{5}+p_{6}\right)-w_{2}^{-}\left(p_{1}+p_{2}+p_{3}+p_{6}\right)\right]+ \\
& u_{2}(1.3) w_{2}^{+}\left(p_{4}\right),
\end{aligned}
$$

when $25<x_{2}^{*}<26.3$,

$$
\begin{aligned}
V(f, h)= & u_{1}(-25)\left[w_{1}^{-}\left(p_{1}+p_{4}\right)-w_{1}^{-}\left(p_{4}\right)\right]+ \\
& u_{1}(-10)\left[w_{1}-\left(p_{1}+p_{2}+p_{4}+p_{5}+p_{6}\right)-w_{1}^{-}\left(p_{1}+p_{4}+p_{5}+p_{6}\right)\right]+ \\
& u_{1}(-5)\left[w_{1}^{-}\left(p_{1}+p_{2}+p_{3}+p_{4}+p_{5}+p_{6}\right)-w_{1}^{-}\left(p_{1}+p_{2}+p_{4}+p_{5}+p_{6}\right)\right]+ \\
& u_{1}(-35) w_{1}^{-}\left(p_{4}\right)+ \\
& u_{1}(-20)\left[w_{1}^{-}\left(p_{1}+p_{4}+p_{5}\right)-w_{1}^{-}\left(p_{1}+p_{4}\right)\right]+ \\
& u_{1}(-15)\left[w_{1}-\left(p_{1}+p_{4}+p_{5}+p_{6}\right)-w_{1}^{-}\left(p_{1}+p_{4}+p_{5}\right)\right]+ \\
& u_{2}\left(1.3-x_{2}\right) w_{2}^{-}\left(p_{3}\right)+ \\
& u_{2}\left(6.3-x_{2}\right)\left[w_{2}^{-}\left(p_{2}+p_{3}\right)-w_{2}^{-}\left(p_{3}\right)\right]+ \\
& u_{2}(-18.7)\left[w_{2}^{-}\left(p_{2}+p_{3}+p_{1}\right)-w_{2}^{-}\left(p_{2}+p_{3}\right)\right]+ \\
& u_{2}\left(21.3-x_{2}^{*}\right)\left[w_{2}^{-}\left(p_{2}+p_{3}+p_{1}+p_{6}\right)-w_{2}^{-}\left(p_{2}+p_{3}+p_{1}\right)\right]+ \\
& u_{2}\left(26.3-x_{2}^{*}\right)\left[w_{2}^{+}\left(p_{5}+p_{4}\right)-w_{2}^{+}\left(p_{4}\right)\right]+ \\
& u_{2}(1.3) w_{2}^{+}\left(p_{4}\right),
\end{aligned}
$$

when $21.3 \leq x_{2}{ }^{*} \leq 25$,

$$
\begin{aligned}
V(f, h)= & u_{1}(-25)\left[w_{1}^{-}\left(p_{1}+p_{4}\right)-w_{1}^{-}\left(p_{4}\right)\right]+ \\
& u_{1}(-10)\left[w_{1}^{-}\left(p_{1}+p_{2}+p_{4}+p_{5}+p_{6}\right)-w_{1}^{-}\left(p_{1}+p_{4}+p_{5}+p_{6}\right)\right]+ \\
& u_{1}(-5)\left[w_{1}^{-}\left(p_{1}+p_{2}+p_{3}+p_{4}+p_{5}+p_{6}\right)-w_{1}^{-}\left(p_{1}+p_{2}+p_{4}+p_{5}+p_{6}\right)\right]+
\end{aligned}
$$




$$
\begin{aligned}
& u_{1}(-35) w_{1}^{-}\left(p_{4}\right)+ \\
& u_{1}(-20)\left[w_{1}^{-}\left(p_{1}+p_{4}+p_{5}\right)-w_{1}^{-}\left(p_{1}+p_{4}\right)\right]+ \\
& u_{1}(-15)\left[w_{1}^{-}\left(p_{1}+p_{4}+p_{5}+p_{6}\right)-w_{1}^{-}\left(p_{1}+p_{4}+p_{5}\right)\right]+ \\
& u_{2}\left(1.3-x_{2}\right) w_{2}^{-}\left(p_{3}\right)+ \\
& u_{2}(-18.7)\left[w_{2}-\left(p_{1}+p_{3}\right)-w_{2}^{-}\left(p_{3}\right)\right]+ \\
& u_{2}\left(6.3-x_{2}\right)\left[w_{2}-\left(p_{1}+p_{3}+p_{2}\right)-w_{2}^{-}\left(p_{1}+p_{3}\right)\right]+ \\
& u_{2}\left(21.3-x_{2}^{*}\right)\left[w_{2}^{-}\left(p_{1}+p_{3}+p_{2}+p_{6}\right)-w_{2}^{-}\left(p_{1}+p_{3}+p_{2}\right)\right]+ \\
& u_{2}(1.3)\left[w_{2}^{+}\left(p_{4}+p_{5}\right)-w_{2}^{+}\left(p_{5}\right)\right]+ \\
& u_{2}\left(26.3-x_{2}^{*}\right) w_{2}^{+}\left(p_{5}\right)
\end{aligned}
$$

when $20 \leq x_{2}{ }^{*} \leq 21.3$,

$$
\begin{aligned}
V(f, h)= & u_{1}(-25)\left[w_{1}-\left(p_{1}+p_{4}\right)-w_{1}^{-}\left(p_{4}\right)\right]+ \\
& u_{1}(-10)\left[w_{1}^{-}\left(p_{1}+p_{2}+p_{4}+p_{5}+p_{6}\right)-w_{1}^{-}\left(p_{1}+p_{4}+p_{5}+p_{6}\right)\right]+ \\
& u_{1}(-5)\left[w_{1}^{-}\left(p_{1}+p_{2}+p_{3}+p_{4}+p_{5}+p_{6}\right)-w_{1}^{-}\left(p_{1}+p_{2}+p_{4}+p_{5}+p_{6}\right)\right]+ \\
& u_{1}(-35) w_{1}^{-}\left(p_{4}\right)+ \\
& u_{1}(-20)\left[w_{1}^{-}\left(p_{1}+p_{4}+p_{5}\right)-w_{1}^{-}\left(p_{1}+p_{4}\right)\right]+ \\
& u_{1}(-15)\left[w_{1}^{-}\left(p_{1}+p_{4}+p_{5}+p_{6}\right)-w_{1}^{-}\left(p_{1}+p_{4}+p_{5}\right)\right]+ \\
& u_{2}\left(1.3-x_{2}\right) w_{2}^{-}\left(p_{3}\right)+ \\
& u_{2}(-18.7)\left[w_{2}^{-}\left(p_{1}+p_{3}\right)-w_{2}^{-}\left(p_{3}\right)\right]+ \\
& u_{2}\left(6.3-x_{2}\right)\left[w_{2}-\left(p_{1}+p_{3}+p_{2}\right)-w_{2}^{-}\left(p_{1}+p_{3}\right)\right]+ \\
& u_{2}\left(21.3-x_{2}^{*}\right)\left[w_{2}^{+}\left(p_{4}+p_{5}+p_{6}\right)-w_{2}^{+}\left(p_{4}+p_{5}\right)\right]+ \\
& u_{2}(1.3)\left[w_{2}^{+}\left(p_{4}+p_{5}\right)-w_{2}^{+}\left(p_{5}\right)\right]+ \\
& u_{2}\left(26.3-x_{2}^{*}\right) w_{2}^{+}\left(p_{5}\right),
\end{aligned}
$$

when $6.3 \leq x_{2}{ }^{*} \leq 20$,

$$
\begin{aligned}
V(f, h)= & u_{1}(-25)\left[w_{1}^{-}\left(p_{1}+p_{4}\right)-w_{1}^{-}\left(p_{4}\right)\right]+ \\
& u_{1}(-10)\left[w_{1}^{-}\left(p_{1}+p_{2}+p_{4}+p_{5}+p_{6}\right)-w_{1}^{-}\left(p_{1}+p_{4}+p_{5}+p_{6}\right)\right]+ \\
& u_{1}(-5)\left[w_{1}^{-}\left(p_{1}+p_{2}+p_{3}+p_{4}+p_{5}+p_{6}\right)-w_{1}^{-}\left(p_{1}+p_{2}+p_{4}+p_{5}+p_{6}\right)\right]+ \\
& u_{1}(-35) w_{1}^{-}\left(p_{4}\right)+ \\
& u_{1}(-20)\left[w_{1}-\left(p_{1}+p_{4}+p_{5}\right)-w_{1}^{-}\left(p_{1}+p_{4}\right)\right]+ \\
& u_{1}(-15)\left[w_{1}^{-}\left(p_{1}+p_{4}+p_{5}+p_{6}\right)-w_{1}^{-}\left(p_{1}+p_{4}+p_{5}\right)\right]+ \\
& u_{2}(-18.7) w_{2}^{-}\left(p_{1}\right)+ \\
& u_{2}\left(1.3-x_{2}\right)\left[w_{2}-\left(p_{1}+p_{3}\right)-w_{2}^{-}\left(p_{1}\right)\right]+ \\
& u_{2}\left(6.3-x_{2}\right)\left[w_{2}^{-}\left(p_{1}+p_{3}+p_{2}\right)-w_{2}^{-}\left(p_{1}+p_{3}\right)\right]+ \\
& u_{2}(1.3)\left[w_{2}^{+}\left(p_{4}+p_{5}+p_{6}\right)-w_{2}^{+}\left(p_{5}+p_{6}\right)\right]+ \\
& u_{2}\left(21.3-x_{2}^{*}\right)\left[w_{2}+\left(p_{5}+p_{6}\right)-w_{2}^{+}\left(p_{5}\right)\right]+
\end{aligned}
$$

when $1.3<x_{2}{ }^{*} \leq 6.3$, 


$$
\begin{aligned}
V(f, h)= & u_{1}(-25)\left[w_{1}^{-}\left(p_{1}+p_{4}\right)-w_{1}^{-}\left(p_{4}\right)\right]+ \\
& u_{1}(-10)\left[w_{1}^{-}\left(p_{1}+p_{2}+p_{4}+p_{5}+p_{6}\right)-w_{1}^{-}\left(p_{1}+p_{4}+p_{5}+p_{6}\right)\right]+ \\
& u_{1}(-5)\left[w_{1}^{-}\left(p_{1}+p_{2}+p_{3}+p_{4}+p_{5}+p_{6}\right)-w_{1}^{-}\left(p_{1}+p_{2}+p_{4}+p_{5}+p_{6}\right)\right]+ \\
& u_{1}(-35) w_{1}^{-}\left(p_{4}\right)+ \\
& u_{1}(-20)\left[w_{1}^{-}\left(p_{1}+p_{4}+p_{5}\right)-w_{1}^{-}\left(p_{1}+p_{4}\right)\right]+ \\
& u_{1}(-15)\left[w_{1}^{-}\left(p_{1}+p_{4}+p_{5}+p_{6}\right)-w_{1}^{-}\left(p_{1}+p_{4}+p_{5}\right)\right]+ \\
& u_{2}(-18.7) w_{2}^{-}\left(p_{1}\right)+ \\
& u_{2}\left(1.3-x_{2}\right)\left[w_{2}^{-}\left(p_{1}+p_{3}\right)-w_{2}^{-}\left(p_{1}\right)\right]+ \\
& u_{2}\left(6.3-x_{2}\right)\left[w_{2}^{+}\left(p_{2}+p_{4}+p_{5}+p_{6}\right)-w_{2}^{+}\left(p_{4}+p_{5}+p_{6}\right)\right]+ \\
& u_{2}(1.3)\left[w_{2}^{+}\left(p_{4}+p_{5}+p_{6}\right)-w_{2}^{+}\left(p_{5}+p_{6}\right)\right]+ \\
& u_{2}\left(21.3-x_{2}^{*}\right)\left[w_{2}^{+}\left(p_{5}+p_{6}\right)-w_{2}^{+}\left(p_{5}\right)\right]+ \\
& u_{2}\left(26.3-x_{2}^{*}\right) w_{2}^{+}\left(p_{5}\right),
\end{aligned}
$$

when $0<x_{2}^{*} \leq 1.3$,

$$
\begin{aligned}
V(f, h)= & u_{1}(-25)\left[w_{1}^{-}\left(p_{1}+p_{4}\right)-w_{1}^{-}\left(p_{4}\right)\right]+ \\
& u_{1}(-10)\left[w_{1}^{-}\left(p_{1}+p_{2}+p_{4}+p_{5}+p_{6}\right)-w_{1}^{-}\left(p_{1}+p_{4}+p_{5}+p_{6}\right)\right]+ \\
& u_{1}(-5)\left[w_{1}^{-}\left(p_{1}+p_{2}+p_{3}+p_{4}+p_{5}+p_{6}\right)-w_{1}^{-}\left(p_{1}+p_{2}+p_{4}+p_{5}+p_{6}\right)\right]+ \\
& u_{1}(-35) w_{1}^{-}\left(p_{4}\right)+ \\
& u_{1}(-20)\left[w_{1}^{-}\left(p_{1}+p_{4}+p_{5}\right)-w_{1}^{-}\left(p_{1}+p_{4}\right)\right]+ \\
& u_{1}(-15)\left[w_{1}^{-}\left(p_{1}+p_{4}+p_{5}+p_{6}\right)-w_{1}^{-}\left(p_{1}+p_{4}+p_{5}\right)\right]+ \\
& u_{2}(-18.7) w_{2}^{-}\left(p_{1}\right)+ \\
& u_{2}\left(1.3-x_{2}\right)\left[w_{2}^{+}\left(p_{3}+p_{2}+p_{4}+p_{5}+p_{6}\right)-w_{2}^{+}\left(p_{2}+p_{4}+p_{5}+p_{6}\right)\right]+ \\
& u_{2}\left(6.3-x_{2}\right)\left[w_{2}^{+}\left(p_{2}+p_{4}+p_{5}+p_{6}\right)-w_{2}^{+}\left(p_{4}+p_{5}+p_{6}\right)\right]+ \\
& u_{2}(1.3)\left[w_{2}^{+}\left(p_{4}+p_{5}+p_{6}\right)-w_{2}^{+}\left(p_{5}+p_{6}\right)\right]+ \\
& u_{2}\left(21.3-x_{2}^{*}\right)\left[w_{2}^{+}\left(p_{5}+p_{6}\right)-w_{2}^{+}\left(p_{5}\right)\right]+ \\
& u_{2}\left(26.3-x_{2}^{*}\right) w_{2}^{+}\left(p_{5}\right) .
\end{aligned}
$$

From the curve of the piecewise function, we can find it is monotonous increasing. Thus, the optimal valuation of $x_{2}$ is 50 and the optiaml valuation of $V(f, h)$ is -11.0189 which is smaller than zero. Thus the company wouldn't abandon land 1 and rebid for land 2 .

\subsection{Event-sequential auctions}

As we have mentioned, in this situation, there are four land auctions. The four auctions are available at different time. The forth auction is proposed after the development outcomes of the previous three auctions have been certain. In this situation, the company has experienced profits of the previous three land development projects. And the company is now trying to bid for the forth land auction. Now we consider the influence of previous profits on the next land auction's bidding price decision.
Suppose that the previous outcomes are as follows: (25 months, 18), (20 months, 15), (30 months, 22 ). Now we would predict the reference point of the next bidding. As we have stated, the reference point of the next bidding can be described as (10). And as the outcomes considered here are of two attributes, we can get two reference points in two attributes, which are denoted as $r 4,1$ and $r 4,2$. According to (17), we can obtain:

$$
\begin{aligned}
& r_{4,1}=\rho_{1}+w_{r_{4,1}}(1 / 3) \times 30+\left[w_{r_{4,1}}(2 / 3)-\right. \\
& \left.w_{r_{4,1}}(1 / 3)\right] \times 25+\left[w_{r_{4,1}}(1)-\right. \\
& \left.w_{r_{4,1}}(2 / 3)\right] \times 20 \\
& r_{4,2}=\rho_{2}+w_{r_{4,2}}(1 / 3) \times 15+\left[w_{r_{4,2}}(2 / 3)-\right. \\
& \left.w_{r_{4,2}}(1 / 3)\right] \times 18+\left[w_{r_{4,2}}(1)-\right. \\
& \left.w_{r_{4,2}}(2 / 3)\right] \times 22 .
\end{aligned}
$$


In (28) and (29), we denote the exponential functions as $w_{r 4,1}$ and $w_{r 4,2}$. Thus the predicted reference point can describe the following characteristic: the best and the worst outcome will have a strong and significant effect on the reference point. We take the following formula which has been proposed by Baucells et al. (2011) with $w_{r_{4,1}}=w_{r_{4,2}}=$ $\exp ^{-(-\ln x)^{0.26} / 1.7}, \rho_{1}=\rho_{1}=5.2$. According to $(28)$ and (29), we can obtain the $r_{4,1}=28.045, r_{4,2}=$ 25.1818. This means the reference point for the forth land of the first attribute is 28.045 , and the reference point for the forth land of the second attribute is 25.1818 . The reference points will make influence on the forthcoming bidding price decision, and the calculation process is similar to the solutions in Sections 5.2 and 5.3. Thus we wouldn't discuss the specific calculation process again.

\section{CONCLUSIONS}

We have discussed bidding strategies when two or more land auctions are involved. We studied the three situations a bidder would probably be faced with when two or more land auctions are considered: the simultaneous situation, the time sequential situation and the event sequential situation. In addition to influential factor analysis, all the land auctions model are constructed as multiattribute auctions, which is more in line with the reality. Then, we applied the prospect theory to predict bidding strategies, taking individual preference into account.

In the simultaneous auctions, the additive utility functions in cumulative prospect theory (CPT) are utilized to solve the bidding decisions, when two auctions of land are available at the same moment. The optimal bidding prices are obtained for both of the two auctions with a limited available fund. In the time-sequential auctions, additive utility function in PT3 is used when two auctions are available at different time. The decision-maker has been endowed with the first land but without knowing the ultimate outcome of the first land. To predict the choice of the company, we supposed the company would abandon the first land and rebid for the second, then we predicted the most possible bidding price that the company would rebid for the second land. We discussed willingness-to-accept (WTA) valuation of the first land when two attributes are considered and applied the additive utility function in third-generation prospect theory (PT3) to solve this problem. In the event-sequential auctions, the prediction of reference point is applied to bidding strategies. We used the predicted ref- erence point to solve the bidding strategies when the outcomes of the previous auctions are known. By calculating the reference point for the upcoming auction, the optimal bidding price for the upcoming auction can be obtained. A case study in Hangzhou, China is used to show the real estate company's land auction bidding decision process and the final optimal solutions are obtained using our proposed prospect-theory based land auction bidding decision model.

\section{ACKNOWLEDGEMENT}

The authors are very grateful to the editors especially Professor Hui, and the anonymous referees and for their many valuable comments and suggestions that greatly improve this paper both in contents and representations.

This work was supported in part by the National Science Foundation of China (NSFC) (71171048, 71371049) and Ph.D. Program Foundation of Chinese Ministry of Education (20120092110038).

\section{REFERENCES}

Abdellaoui, M. 2000. Parameter-free elicitation of utility and probability weighting functions, Management Science 46(11): 1497-1512. http://dx.doi.org/10.1287/ mnsc.46.11.1497.12080

Armantier, O.; Treich, N. 2009. Star-shaped probability weighting functions and overbidding in first-price auctions, Economics Letters 104(2): 83-85. http:// dx.doi.org/10.1016/j.econlet.2009.04.016

Barberis, N.; Xiong, W. 2009. What drives the disposition effect? An analysis of a long-standing preference-based explanation, Journal of Finance 64(2): 751-784. http://dx.doi.org/10.1111/j.15406261.2009.01448.x

Baucells, M.; Weber, M.; Welfens, F. 2011. Referencepoint formation and updating, Management Science 57(3): 506-519. http://dx.doi.org/10.1287/ mnsc. 1100.1286

Bichler, M. 2000. An experimental analysis of multi-attribute auction, Decision Support Systems 29(3): 249268. http://dx.doi.org/10.1016/S0167-9236(00)00075-0

Bleichrodt, H.; Schmidt, U.; Zank, H. 2009. Additive utility in prospect theory, Management Science 55(5): 863-873. http://dx.doi.org/10.1287/mnsc.1080.0978

Camerer, C. F. 2000. Prospect theory in the wild: evidence from the field. Cambridge University.

Chau, K. W.; Wong, S. K.; Yiu, C. Y. 2010. Do unexpected land auction outcomes bring new information to the real estate market?, Journal of Real Estate Finance and Economics 40(4): 480-496. http://dx.doi. org/10.1007/s11146-009-9220-0

Che, Y. K. 1993. Design competition through multidimensional auctions, RAND Journal of Economics 24(4): 668-680. http://dx.doi.org/10.2307/2555752 
Chen, Q.; Fan, M. 2008. Competitive bidding in urban land auctions with incentive contracts, in International Seminar on Business and Information Management, 19 December 2008, Wuhan, 437-440. http:// dx.doi.org/10.1109/ISBIM.2008.223

Chen-Ritzo, C. H.; Harrison, T.; Kwasnica, A. M.; Thomas, D. 2003. Better, faster, cheaper: a multi-attribute supply chain auction mechanism: Technical report. Institute for the Study of Business Markets, The Pennsylvania State University.

Cheng, M. Y.; Hsiang, C. C.; Tsai, H. C.; Do, H. L. 2011. Bidding decision making for construction company using a multi-criteria prospect mode, Journal of Civil Engineering and Management 17(3): 424-436. http:// dx.doi.org/10.3846/13923730.2011.598337

Davis, A. M.; Katok, E.; Kwasnica, A. M. 2011. Do auctioneers pick optimal reserve prices?, Management Science 57(1): 177-192. http://dx.doi.org/10.1287/ mnsc. 1100.1258

Fan, Z.-P.; Zhang, X.; Chen, F.-D.; Liu, Y. 2013. Extended TODIM method for hybrid MADM problems, Knowledge-Based Systems 42: 40-48. http://dx.doi. org/10.1016/j.knosys.2012.12.014

Farquhar, P. H. 1975. A fractional hypercube decomposition theorem for multi-attribute utility functions, Operations Research 23(5): 941-967. http://dx.doi. org/10.1287/opre.23.5.941

Fischer, G. W.; Kamlet, M. S.; Fienberg, S. E.; Schkade, D. 1986. Risk preferences for gains and losses in multiple objective decision making, Management Science 32(9): 1065-1086. http://dx.doi. org/10.1287/mnsc.32.9.1065

Friedman, L. A. 1956. A competitive bidding strategy, Operations Research 4(1): 104-112. http://dx.doi. org/10.1287/opre.4.1.104

Kahneman, D.; Tversky, A. 1979. Prospect theory: an analysis of decision under risk, Econometrica 47: 263-291. http://dx.doi.org/10.2307/1914185

Keeney, R. L.; Raiffa, H. 1993. Decisions with multiple objectives: preferences and value trade-offs. Cambridge University Press, UK. http://dx.doi. org/10.1017/CBO9781139174084

Knetsch, J. L.; Sinden, J. A. 1984. Willingness to pay and compensation demanded: experimental evidence of an unexpected disparity in measures of value, Quarterly Journal of Economics 99(3): 507-521. http://dx.doi.org/10.2307/1885962

Liu, P. D. 2009. Multi-attribute decision making method research based on interval vague set and TOPSIS method, Technological and Economic Development of Economy 15(3): 453-463. http://dx.doi. org/10.3846/1392-8619.2009.15.453-463

Loomes, G.; Starmer, C.; Sugden, R. 2003. Do anomalies disappear in repeated markets?, Economic Journal 113: 153-166. http://dx.doi.org/10.1111/14680297.00108

McAfee, R. P.; McMillan, J. 1987. Auctions and bidding, Journal of Economic Literature 25(2): 699-738.
Myerson, R. B. 1981. Optimal auction design, Mathematics of Operations Research 6(1): 58-73. http:// dx.doi.org/10.1287/moor.6.1.58

Quiggin, J. C. 1981. Risk perception and the analysis of risk attitudes, Australian Journal of Agricultural Economics 25: 160-169. http://dx.doi. org/10.1111/j.1467-8489.1981.tb00393.x

Quiggin, J. C. 1982. A theory of anticipated utility, Journal of Economic Behavior and Organization 3(4): 323-343. http://dx.doi.org/10.1016/01672681(82)90008-7

Ratan, A. 2010. Applying prospect theory to auctions: $\mathrm{PhD}$ thesis. University of Maryland.

Richard, E. W. 1980. Auctions and bidding models: a survey, Management Science 26(2): 119-142. http:// dx.doi.org/10.1287/mnsc.26.2.119

Riley, G. J.; Samuelson, W. F. 1981. Optimal auctions, American Economic Review 71(3): 381-392.

Schmidt, U.; Starmer, C.; Sugden, R. 2008. Third-generation prospect theory, Journal of Risk and Uncertainty 36: 203-223. http://dx.doi.org/10.1007/s11166008-9040-2

Shash, A. A.; AbdulHadi, N. H. 1992. Factors affecting a contractors markup size decision in Saudi Arabia, Construction Management and Economics 10(5): 415429. http://dx.doi.org/10.1080/01446199200000039

Stankevičienè, J.; Mencaitè, E. 2010. The evaluation of bank performance using a multicriteria decision making model: a case study on Lithuanian commercial banks, Technological and Economic Development of Economy 18: 189-205. http://dx.doi.org/10.3846/20 294913.2012 .668373

Thiel, S. E. 1988. Multidimensional auctions, Economics Letters 28: 37- 40. http://dx.doi.org/10.1016/01651765(88)90068-7

Tversky, A.; Kahneman, D. 1992. Advances in prospect theory: cumulative representation of uncertainty, Journal of Risk and Uncertainty 5: 297-323. http:// dx.doi.org/10.1007/BF00122574

Vickrey, W. 1961. Counterspeculation, auctions, and competitive sealed tenders, Journal of Finance 16(1): 8-37. http://dx.doi.org/10.1111/j.1540-6261.1961. tb02789.x

Wilson, R. 1977. A bidding model of perfect competition, Review of Economic Studies 44(3): 511-518. http:// dx.doi.org/10.2307/2296904

Wu, W. Y.; Lin, B. S.; Cheng, C. F. 2009. Evaluating online auction strategy: a theoretical model and empirical exploration, Journal of Computer Information Systems 49(3): 22-30.

Xiong, G. Q.; Zhang, C. S. 2008. Multi-unit auction model based on loss aversion, in Workshop on Knowledge Discovery and Data Mining, 23-24 January 2008, Adelaide, SA, 274-278. http://dx.doi.org/10.1109/ WKDD.2008.39

Zavadskas, E. K.; Turskis, Z.; Tamosaitiene, J.; Marina, V. 2008. Multicriteria selection of project managers by applying grey criteria, Technological and Economic Development of Economy 14(4): 462-477. http://dx.doi.org/10.3846/1392-8619.2008.14.462-477 